\title{
OPEN The role of IL-6-174 G/C polymorphism and intraocular IL-6 levels in the pathogenesis of ocular diseases: a systematic review and meta-analysis
}

\author{
Zulvikar Syambani Ulhaq ${ }^{1 凶}$, Gita Vita Soraya ${ }^{2}{ }^{2}$, Budu $^{3}$ \& Lely Retno Wulandari ${ }^{4}$
}

Interleukin-6 (IL-6) is one of the key regulators behind the inflammatory and pathological process associated with ophthalmic diseases. The role of IL-6-174 G/C polymorphism as well as intraocular IL- 6 levels among various eye disease patients differ across studies and has not been systematically reviewed. Thus, this study aims to provide a summary to understand the relationship between IL- 6 and ophthalmic disease. In total, 8,252 and 11,014 subjects for IL-6-174 G/C and intraocular levels of IL-6, respectively, were retrieved from PubMed, Scopus and Web of Science. No association was found between IL-6-174 G/C polymorphisms with ocular diseases. Subgroup analyses revealed a suggestive association between the GC genotype of IL-6-174 G/C with proliferative diabetic retinopathy (PDR). Further, the level of intraocular IL- 6 among ocular disease patients in general was found to be higher than the control group [standardized mean difference (SMD) $=1.41,95 \%$ confidence interval $(\mathrm{Cl}) 1.24$ $1.58, \mathrm{P}<0.00001]$. Closer examination through subgroup analyses yielded similar results in several ocular diseases. This study thus indicates that the IL-6-174 G/C polymorphism does not predispose patients to ocular disease, although the GC genotype is likely to be a genetic biomarker for PDR. Moreover, intraocular IL-6 concentrations are related to the specific manifestations of the ophthalmic diseases. Further studies with larger sample sizes are warranted to confirm this conclusion.

Ocular diseases are known to adversely affect the quality of life. The most common ocular diseases such as uveitis, glaucoma, age-related macular degeneration (AMD), diabetic retinopathy (DR) and cataract can cause a spectrum of sequelae ranging from visual impairment to irreversible blindness ${ }^{1}$. Inflammation is a normal biological response towards pathogen invasion or host tissue injury ${ }^{2}$, and has been known to play a crucial role in the development and progression of ocular disease ${ }^{3}$. Although previous studies of the involvement of inflammation has been limited to the pathogenesis of inflammatory disorders such as uveitis and dry eye disease (DED) $)^{3,4}$, it is now widely implicated in many other ophthalmic pathologies ${ }^{1}$. Thus, understanding of key inflammatory mechanisms may allow the development of early detection strategies and prompt treatment for ocular disease patients.

The inflammation process is modulated by cytokines via complex cellular interactions ${ }^{5}$. The ocular tissue is no exception, as certain inflammatory cytokines have been implicated in eye disease pathogenesis, with IL-6 playing a prominent role in particular ${ }^{6}$ through its pleiotropic action as both a pro- and anti-inflammatory mediator $^{7,8}$. IL-6 protein expression is regulated by the IL- 6 gene located on chromosome $7 \mathrm{p} 21^{9}$, on which several polymorphisms have been reported. The highly frequent IL-6-174 G/C (rs1800795) polymorphism is of particular importance, due to its functional effect on IL-6 promoter activity, which then influences basal IL-6 levels ${ }^{10-14}$. Several studies have also reported the association between IL-6-174 G/C polymorphism with ocular diseases ${ }^{15-37}$. However, the results are equivocal, and the causal relationship between IL-6 gene mutations and ocular pathologies remain unclear.

\footnotetext{
${ }^{1}$ Department of Biochemistry, Faculty of Medicine and Health Sciences, Maulana Malik Ibrahim State Islamic University of Malang, Batu, East Java 65151, Indonesia. ${ }^{2}$ Department of Biochemistry, Faculty of Medicine, Hasanuddin University, Makassar, South Sulawesi, Indonesia. ${ }^{3}$ Department of Ophthalmology, Faculty of Medicine, Hasanuddin University, Makassar, South Sulawesi, Indonesia. ${ }^{4}$ Department of Ophthalmology, Faculty of Medicine, Brawijaya University, Malang, East Java, Indonesia. ${ }^{\varpi}$ email: zulhaq@kedokteran.uin-malang.ac.id
} 
Localised expression of IL- 6 has been detected in the anterior segment of human eyes, such as within the trabecular meshwork (TM) and endothelial cells of Schlemm's canal (SC) $)^{38}$. In pathologic conditions such as wet AMD, immunohistochemistry of human choroidal fibrovascular tissues show strong positive staining in the stroma and retinal pigment epithelial (RPE) cells ${ }^{39}$, implicating the role of ocular IL-6 production in disease pathogenesis. Elevated IL-6 concentrations have also been found in the serum, tears and intraocular fluids of ocular diseases patients ${ }^{40-43}$, although results of serum IL-6 measurements are often inconsistent compared to those derived from intraocular fluid ${ }^{43,44}$. This implies that aqueous and vitreous humours more reliably reflect the immunological conditions of the eye compared to serum, and hence assessment of intraocular IL-6 levels may be a potential option for early detection of ocular inflammation and assessment of disease progression.

Despite said reports on the implications of both genotypic distributions and intraocular IL-6 level among various ophthalmic patients, results still vary across studies and has not been systematically reviewed to date. Therefore, a systematic review and meta-analysis was conducted from eligible studies to evaluate the association between IL-6-174 G/C polymorphism and to estimate intraocular IL-6 levels among various eye disease patients.

\section{Results}

Association between IL-6-174 G/C polymorphism with the ocular diseases. In the literature search, a total of 40 articles were retrieved from databases. Among them, 30 were found to be relevant based on the study criteria. Seven studies were then excluded due to insufficient genotypic or allelic data. Finally, 23 studies investigating the association between IL-6-174 G/C polymorphism and ocular disease were included in this meta-analysis ${ }^{15-37}$ (Fig. 1A).

The 23 studies yielded a total of 8,252 subjects, which were then divided into five groups for analysis, namely glaucoma, retinopathy, surface and intraocular inflammation, vascular occlusion and congenital eye disorders. Peripheral blood sampling was used for DNA extraction followed by polymerase chain reaction (PCR)-genotyping for all the studies included in this meta-analysis. All but 4 of the studies complied with the Hardy-Weinberg equilibrium (HWE, $\mathrm{P}>0.05)^{21,22,25,28}$. Details of the retrieved studies are shown in Supplemental Table S1.

The pooled result of the analysis is shown in Supplemental Table S2. Overall (1a and b), there was no significant association between IL-6-174 G/C polymorphism with the risk of ocular disease in any inheritance model, either with or without the inclusion of the four studies that deviated from the HWE (Supplemental Table S2). Similarly, subgroup analyses classified by ethnicity or racial descent $(10,11)$ showed no significant association in all inheritance models (Supplemental Table S2). However, subgroup analyses stratified by the type of disease [glaucoma (2), retinopathy (3a and b), DR (4), PDR (5), ocular and intraocular inflammation (6a and b), Graves' ophthalmology (7), ocular Behcet's disease (8), and retinal vascular occlusion (9)] revealed marginally significant associations of IL-6-174 G/C polymorphism in only the overdominant (GC vs. CC + GG, odds ratio $(\mathrm{OR})=1.34,95 \%$ CI 1.03-1.75, $\mathrm{P}=0.028, \mathrm{I}^{2}=58.45 \%$, Fig. 1C, (Supplemental Table S2) and heterozygous (GC vs. GG, OR $=1.33,95 \%$ CI 1.01-1.76, $\mathrm{P}=0.045, \mathrm{I}^{2}=40.79 \%$, Fig. 1D, (Supplemental Table S2) models of PDR subtype (5). Begg's funnel plot (Supplemental Fig. S1A-G) and Egger's test were applied, and no publication bias was observed ( $\mathrm{P}_{\text {Egger's test }}>0.05$, Supplemental Table $\mathrm{S} 2$ ). A sensitivity analysis was conducted by eliminating one individual study each time (Supplemental Figs. S2-S5), yet associations detected in pooled analyses remained unchanged in all inheritance models, suggesting robustness of the findings.

The association between IL-6 levels and overall risk of ocular diseases. A total of 1,203 potentially relevant studies were initially detected. After reviewing the titles, abstract and full-text availability, 875 articles were excluded. Out of the 328 studies subsequently assessed, 169 were rejected because they did not meet the inclusion criteria. Thus, 159 studies were included in this meta-analysis ${ }^{41-199}$ (Fig. 1B), with the characteristics of the studies summarized in Supplemental Table S3. A total of 11,014 subjects were analysed, with the overall (1) pooled results revealing higher IL-6 levels in ocular disease patients than controls (SMD $=1.41,95 \%$ CI 1.24-1.58, P $<0.00001$, Supplemental Table S4). Analysis of the 17 subgroups yielded significant associations between intraocular IL-6 levels with glaucoma (2), pseudoexfoliation (PEX) syndrome (3), ocular inflammation 4, 4a1, 4b, 4b1-5), DR (5, 5a-c), macular oedema (MO) (6, 6a, and 6b), retinal vascular occlusion (7, 7a-c), retinal detachment (RD) (11), proliferative vitreoretinopathy (PVR) (12), retinopathy of prematurity (ROP) (13), and Coats' disease (14). The strong association was not observed in $\operatorname{AMD}(8,8 \mathrm{a}-\mathrm{c})$, choroidal neovascularization $(\mathrm{CNV})(9)$, pachychoroid spectrum diseases (10), retinitis pigmentosa (RP) (15), epiretinal membrane (ERM) (16) and others (17) (which are consist of pseudophakia, congenital cataract, pseudophakic bullous keratopathy (PBK) and high myopia cataract (HMC)) (Supplemental Table S4). Funnel plots (see Supplemental Figs. S6, S7) and statistical tests (for overall, ocular inflammation, DR, MO, vascular occlusion and AMD: $\mathrm{P}_{\text {Egger's test }}<0.05$, see Supplemental Table S4) provided evidence for substantial publication bias, as there were several studies with a large concentration of IL-6. A trim and fill method was implemented to correct the bias and recalculate the pooled results. However, the results of the meta-analysis remained identical, suggesting that it was not affected by publication bias.

Because substantial heterogeneity was observed in the overall pooled result (Supplemental Table S4), further analysis was performed based on additional subgroups (ethnicity, type of sample and quantification method) and using meta-regression (year of publication, type of disease, type of sample, ethnicity, quantification method and sample size) to evaluate the source of heterogeneity. The results showed that high IL-6 levels remained significantly associated with the presence of ocular disease in all subgroups except the Middle Eastern ethnicity group (Supplemental Table S5). Moreover, meta-regression analysis showed that the type of disease, quantification method and ethnicity were significantly associated with heterogeneity (Supplemental Table S6). The sensitivity analysis indicated that the association between high IL-6 levels and the presence of ocular disease was not excessively influenced by any particular study (Supplemental Fig. S8). 


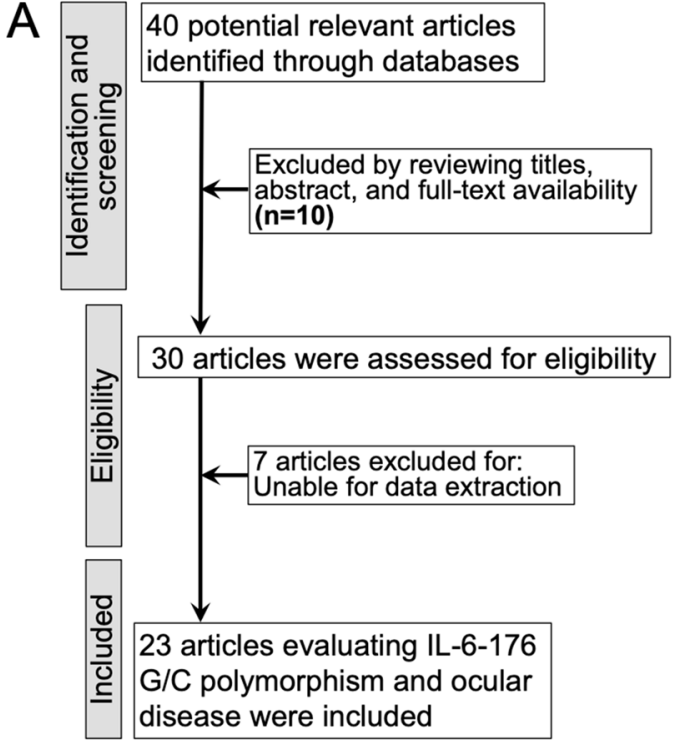

\section{C (GC vs. $G G+C C)$}

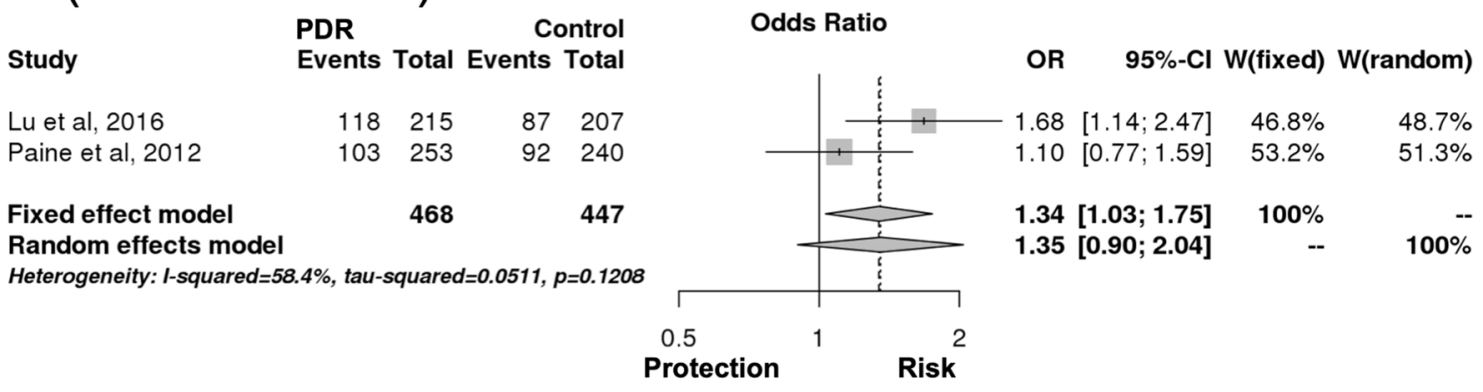

\section{D (GC vs. GG)}

\begin{tabular}{|c|c|c|c|c|}
\hline Study & $\begin{array}{l}\text { PDR } \\
\text { Events }\end{array}$ & Total & $\begin{array}{r}\text { C } \\
\text { Events }\end{array}$ & $\begin{array}{l}\text { Sontrol } \\
\text { Total }\end{array}$ \\
\hline Lu et al, 2016 & 118 & 182 & 87 & 165 \\
\hline Paine et al, 2012 & 103 & 241 & 92 & 232 \\
\hline $\begin{array}{l}\text { Fixed effect model } \\
\text { Random effects model }\end{array}$ & & 423 & & 397 \\
\hline
\end{tabular}

B 1203 potential relevant records identified through databases

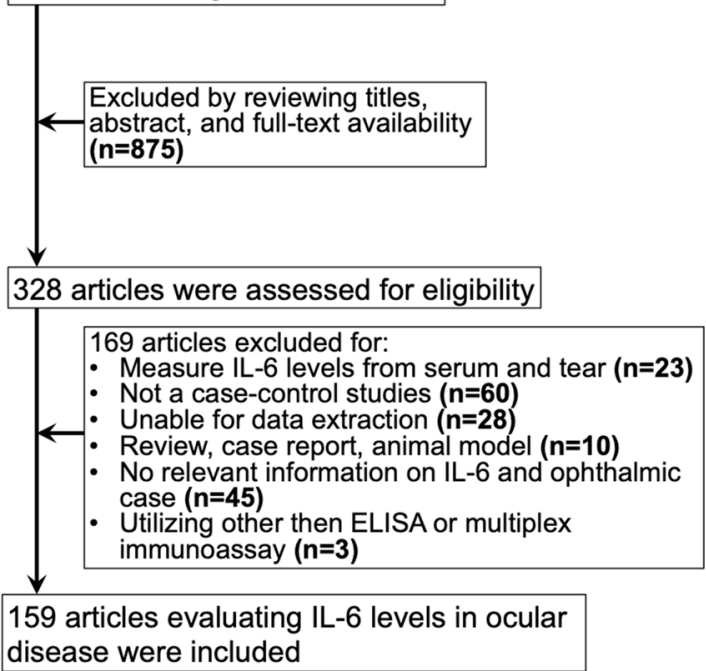

Heterogeneity: $\mathrm{I}$-squared $=40.8 \%$, tau-squared $=0.0287, p=0.1937$

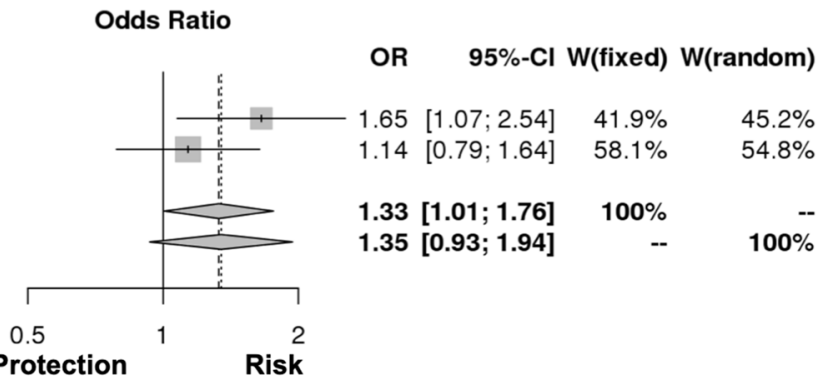

Figure 1. Flow diagram of the study selection process and the association of IL-6-174 G/C polymorphism with diabetic retinopathy. (A) Flow diagram for IL-6-174 G/C polymorphism with the ocular diseases; (B) Flow diagram for intraocular IL-6 levels with the ocular diseases; (C) Association between overdominant model in IL-6-174 G/C polymorphism with proliferative diabetic retinopathy; (D) Association between the heterozygous model in IL-6-174 G/C polymorphism with proliferative diabetic retinopathy.

The association between IL- 6 levels and specific ocular diseases. Glaucoma. Glaucoma (2) was divided into three subgroups, which were primary open-angle glaucoma (POAG) (2a), primary angle-closure glaucoma (PACG) (2b), and secondary glaucoma (2c). Although the pooled result indicated that glaucoma patients tend to have higher IL-6 levels ( $\mathrm{SMD}=0.8,95 \% \mathrm{CI} 0.26-1.35, \mathrm{P}=0.004$, Fig. 2A, Supplemental Table S4), only secondary glaucoma (which contributed $36.2 \%$ towards the total weight) showed a significant increase of IL-6 levels compared to control (SMD = 1.84, 95\% CI 0.59-3.09, $\mathrm{P}=0.004$ ), but not to POAG or PACG (Fig. 2A, Supplemental Table S4). Further analysis revealed that other types of secondary glaucoma (a pool of neovascular glaucoma (NVG), Posner-Schlossman syndrome (PSS), uveitic glaucoma (UG) and secondary glaucoma post silicone oil tamponade) showed significantly higher IL-6 levels (SMD $=2.57,95 \%$ CI $1.20-3.94, \mathrm{P}=0.004$ ) but pseudoexfoliative glaucoma (PEXG) did not show this association (Fig. 2B). However, the PEX syndrome (3) displayed a marginally significant increase of IL-6 levels ( $\mathrm{SMD}=1.56,95 \% \mathrm{CI} 0.19-2.93, \mathrm{P}=0.03$ ) (Fig. 3A, 


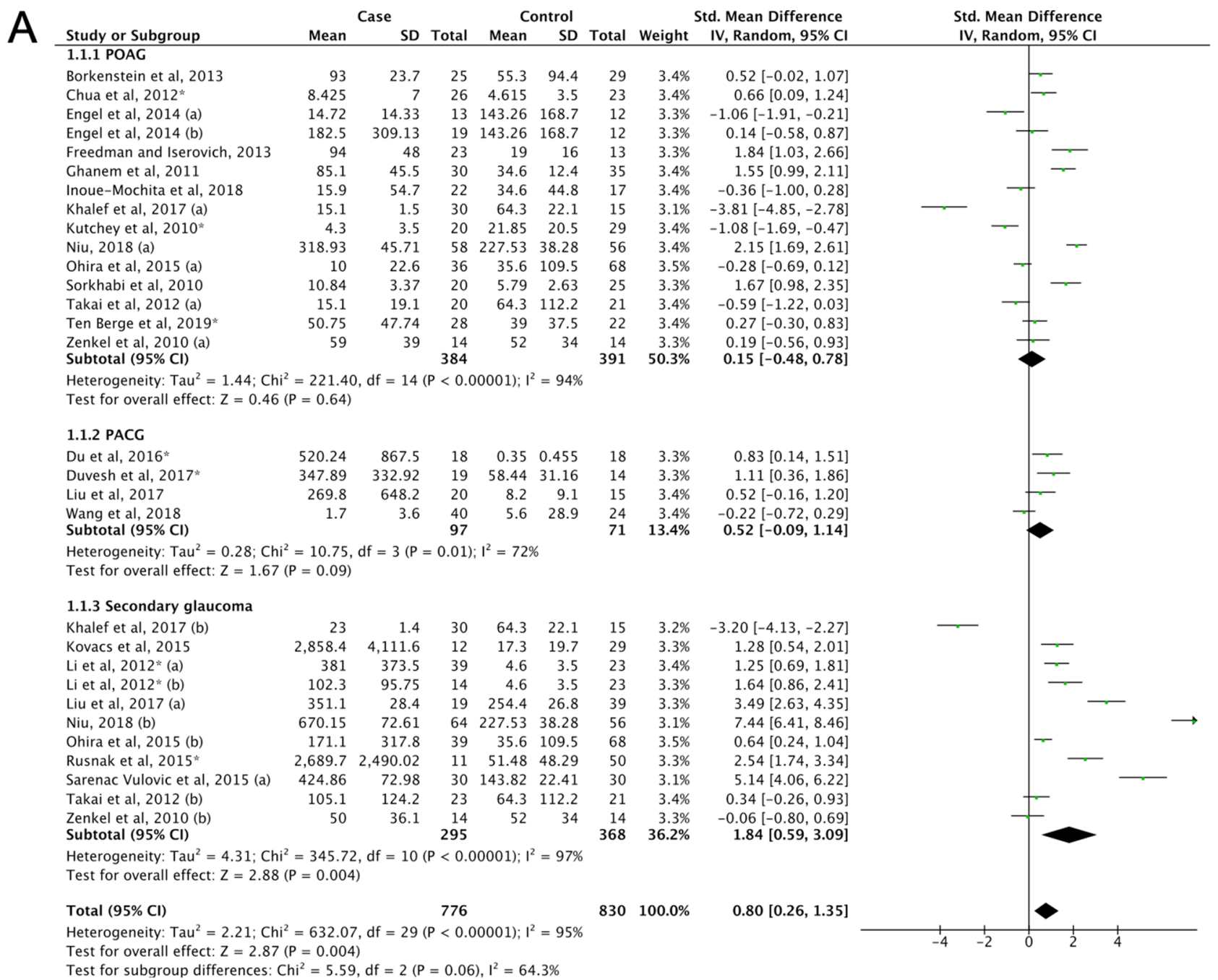

B

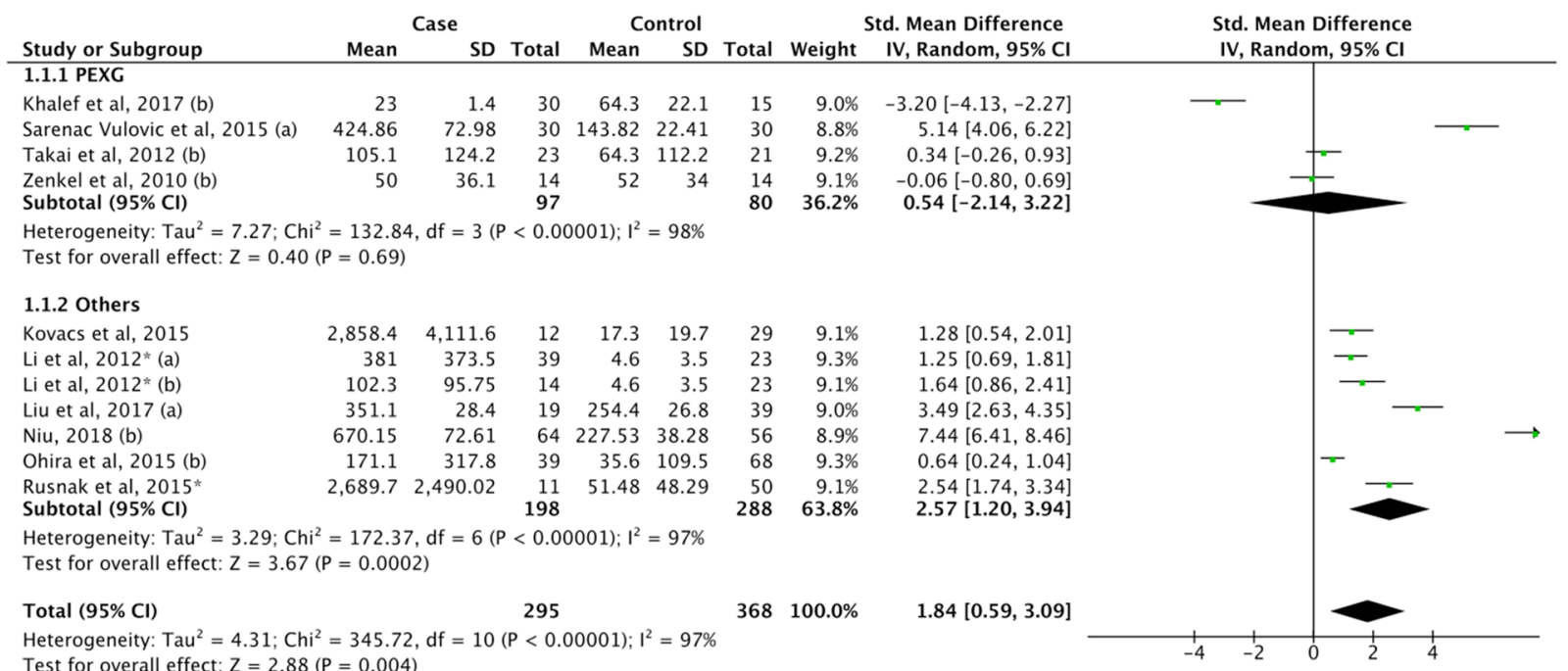

Test for subgroup differences: $\mathrm{Chi}^{2}=1.75, \mathrm{df}=1(\mathrm{P}=0.19), \mathrm{I}^{2}=42.9 \%$

Figure 2. (A) Forest plot for pooled SMD and 95\% CI for IL-6 levels between glaucoma and control; (B) Forest plot for pooled SMD and 95\% CI for IL-6 levels between secondary glaucoma and control. 


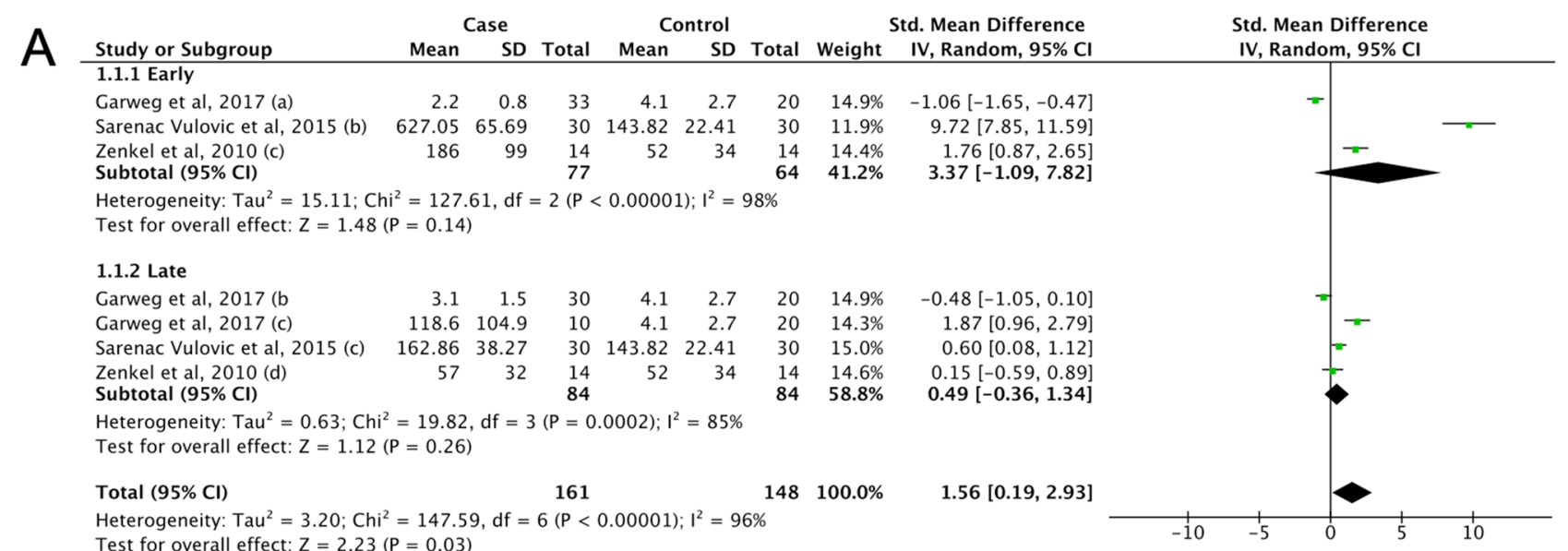

B

Test for overall effect: $Z=2.23(\mathrm{P}=0.03)$

Test for subgroup differences: $\mathrm{Chi}^{2}=1.55, \mathrm{df}=1(\mathrm{P}=0.21), \mathrm{I}^{2}=35.4 \%$

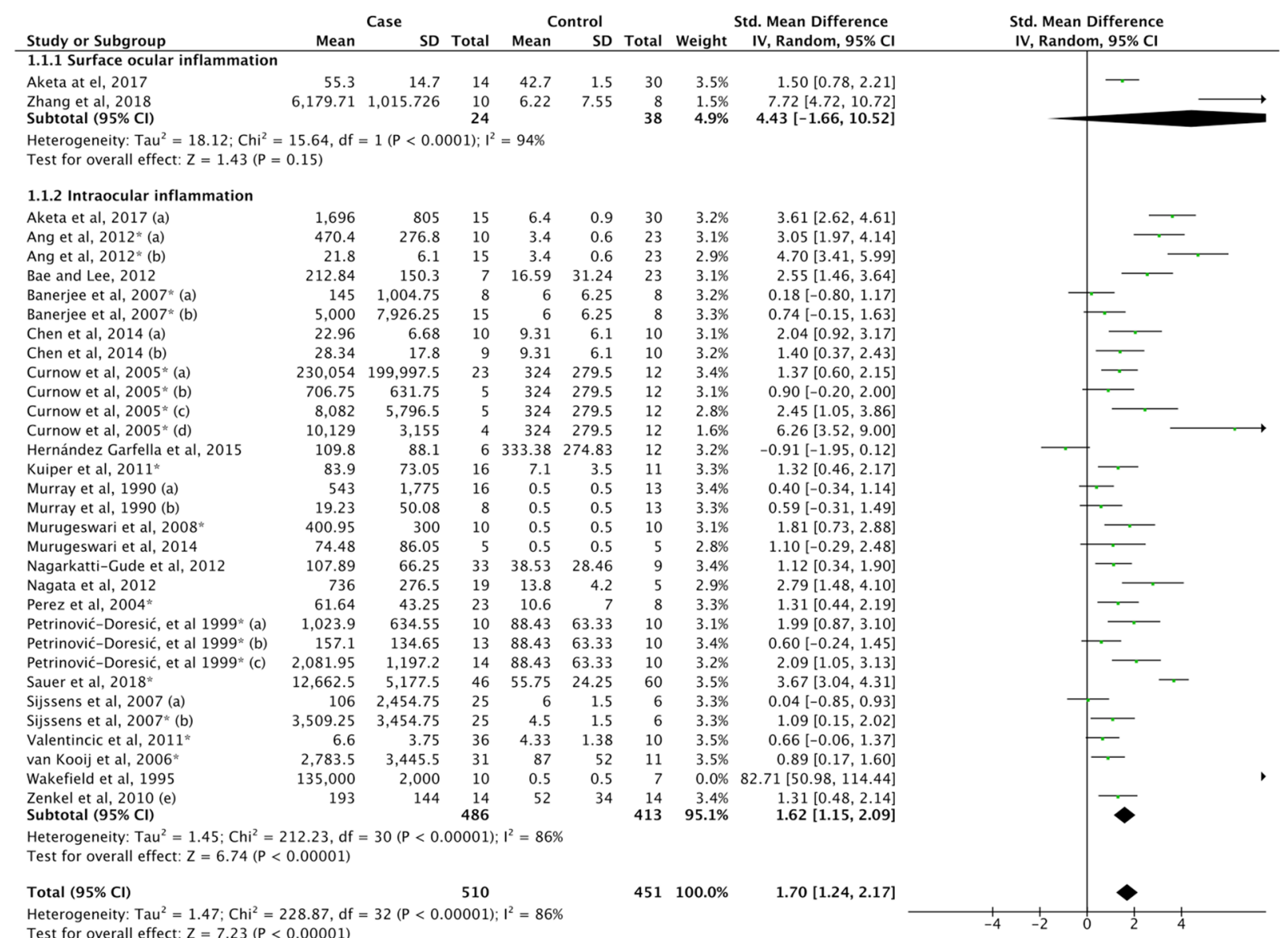

Test for subgroup differences: $\mathrm{Chi}^{2}=0.81, \mathrm{df}=1(\mathrm{P}=0.37), \mathrm{I}^{2}=0 \%$

Figure 3. (A) Forest plot for pooled SMD and 95\% CI for IL-6 levels between PEX syndrome and control; (B) Forest plot for pooled SMD and 95\% CI for IL-6 levels between the ocular inflammation and control.

Supplemental Table S4). No significant difference was found regarding the level of IL-6 between early and late PEX syndrome $(\mathrm{SMD}=1.69,95 \% \mathrm{CI}-1.36-4.74, \mathrm{P}=0.28)$ (Supplemental Fig. S9). No publication biases were detected in the glaucoma and PEX syndrome groups (Supplemental Fig. S6B-C, Supplemental Table S4).

Ocular inflammation. The ocular inflammation group (4) was divided into the surface ocular inflammation (4a) and intraocular inflammation subgroups (4b). In calculating the estimated effect of ocular inflammation, the intraocular inflammation subgroup contributed $95.1 \%$ of the total weight. A significantly higher IL-6 level was found in the intraocular inflammation subgroup ( $\mathrm{SMD}=1.62,95 \% \mathrm{CI} 1.15-2.09, \mathrm{P}<0.00001)$, but not in the surface ocular inflammation subgroup (Fig. 3B, Supplemental Table S4). However, additional meta-analysis confirmed that IL-6 levels in tears of patient with surface ocular diseases displayed a significant increase 
compared to the control subjects (SMD $=2.07,95 \%$ CI 1.67-2.48, $\mathrm{P}<0.00001)^{200-233}$ (Supplemental Fig. S10). Although the funnel plot analysis showed symmetrical distribution of studies and no significant publication bias (Supplemental Fig. S6D), Egger's test indicated publication bias in the intraocular inflammation group (see Supplemental Table S4). However, since no significant change was observed through the trim and fill method, the meta-analysis results for the subgroup of intraocular inflammation were robust. Further subtyping of intraocular inflammation generally consisted of uveitis patients classified based on the aetiology of uveitis (4b1-5). Overall, each subtype indicated the presence of upregulated IL-6 levels, except the unclassified uveitis subtype (4b1) $(\mathrm{SMD}=0.67,95 \% \mathrm{CI}-0.45-1.79, \mathrm{P}=0.24)$ (Supplemental Table S4, Supplemental Fig. S11). However, this result was possibly affected by a single study ${ }^{76}$ that showed oppositional outcome (Supplemental Fig. S11).

Diabetic retinopathy. Although IL-6 levels in DR (5) has been previously examined to some extent ${ }^{234}$, this present meta-analysis has included additional studies $62,65,73,78,79,82,91,92,96,99,101,103,109-112,114,117-120$. The IL-6 levels were found to be higher in DR than in control group ( $\mathrm{SMD}=2.21,95 \% \mathrm{CI} 1.74-2.69, \mathrm{P}<0.00001)$. Subgroup analyses by clinical classification, yielded the same outcome (unclassified DR (5a), SMD =1.97, 95\% CI 1.17-2.76, $\mathrm{P}<0.00001$; PDR, SMD $=2.17,95 \%$ CI 1.55-2.78, $\mathrm{P}<0.00001)(5 \mathrm{~b})$; and non-proliferative diabetic retinopathy (NPDR) (5c), SMD =5.55, 95\% CI 2.67-8.42, $\mathrm{P}<0.00001$ (Fig. 4A, Supplemental Table S4). Intraocular IL-6 levels were lower in NPDR than PDR ( $S M D=-3.40,95 \% \mathrm{CI}-5.93$ to $-0.86, \mathrm{P}=0.009$, Fig. $4 \mathrm{~B})$. A discrepancy between the funnel plot (Supplemental Fig. S6E) and Egger's test was detected (Supplemental Table S4), but the trim and fill method did not leverage the results and the outcome remained similar.

Macular oedema. The pooled results showed that the IL-6 levels in patients with MO (6) was higher than the control group $(\mathrm{SMD}=1.54,95 \% \mathrm{CI} 1.20-1.87, \mathrm{P}<0.00001)$. Because substantial publication bias was reported $\left(\mathrm{P}_{\text {Egger's test }}=0.000\right.$, Supplemental Table S4), a trim and fill method was employed, but the result was still identical. Both diabetic macular oedema (DMO) (6a) and non-DMO (6b) subgroups displayed a significant increase of IL-6 levels relative to controls $(\mathrm{SMD}=1.52,95 \% \mathrm{CI} 1.16-1.89, \mathrm{P}<0.00001$; $\mathrm{SMD}=0.89,95 \% \mathrm{CI} 0.42-1.31$, $\mathrm{P}=0.0001$, respectively) (Fig. 5, Supplemental Table S4). Network meta-analysis to investigate the level of IL-6 in DMO patterns based on optical coherence tomography (OCT) was pooled from three studies ${ }^{121,131,132}$. The resuslts showed that the IL-6 levels in each group were significantly higher than control. The level of IL-6 did not significantly differ between diffuse retinal thickening (DRT), cystoid macular oedema (CMO), and serous retinal detachment (SRD) groups (Supplemental Table S7).

Retinal vascular occlusion. Retinal vascular occlusions (7) consists of the retinal vein occlusion (RVO) and retinal artery occlusion (RAO) subgroups. However, since only one study reported the concentration of IL-6 in $\mathrm{RAO}^{165}$, results on vascular occlusion in this meta-analysis was mainly generated from the pooled RVO studies (7a) (Fig. 6, Supplemental Table S4). There was a significant increase of IL-6 levels in the vascular occlusion group in comparison to control $(\mathrm{SMD}=1.68,95 \% \mathrm{CI} 1.29-2.07, \mathrm{P}<0.00001)$. Subgroups stratified as RVO (7a), central retinal vein occlusion (CRVO) (7b), and branch retinal vein occlusion (BRVO) (7c) showed identically significant associations with higher IL-6 levels (Fig. 6, Supplemental Table S4). However, the IL-6 levels was significantly increased in CRVO than BRVO ( $\mathrm{SMD}=0.75,95 \% \mathrm{CI} 0.25-1.25, \mathrm{P}=0.003$ ) (Supplemental Fig. S12A). Subgroup analyses performed for CRVO and BRVO groups showed higher IL-6 levels in both CRVO or BRVO patients with MO than those without MO (Supplemental Fig. S12B-C). Further, the trim and fill method did not reveal publication bias present in this meta-analysis (Supplemental Fig. S7A, Supplemental Table S4), and the results remained equivalent.

Age-related macular degeneration. The pooled result showed that IL-6 levels in AMD (8) patients did not differ with controls $(\mathrm{SMD}=0.29,95 \% \mathrm{CI}-0.07$ to $0.65, \mathrm{P}=0.11$, Fig. $7 \mathrm{~A})$. However, it should be noted that IL-6 levels tend to be higher in the wet $\mathrm{AMD}$ subgroup ( $\mathrm{SMD}=0.33,95 \% \mathrm{CI}-0.13$ to $0.79, \mathrm{P}=0.16$, Fig. 7A). Thus, studies reporting $\mathrm{CNV}$ in $\mathrm{AMD}$ were then included in subgroup of wet $\mathrm{AMD}$, but the result remained insignificant $(\mathrm{SMD}=0.32,95 \% \mathrm{CI}-0.03$ to $0.66, \mathrm{P}=0.07$, Supplemental Fig. S13A). The IL-6 levels were not different between dry and wet AMD (SMD $=-0.60,95 \% \mathrm{CI}-1.13$ to $0.12, \mathrm{P}=0.10$, Supplemental Fig. S13B). No publication biases were reported (Supplemental Fig. S7B, Supplemental Table S4).

Pachychoroid spectrum diseases. Pachychoroid spectrum diseases (10) are a group of diseases characterized by choroidal thickening, dilated veins and thinning of the choriocapillaris layer ${ }^{235}$. In this meta-analysis, pachychoroid spectrum diseases were classified into the following three disease groups: central serous chorioretinopathy (CSC), pachychoroid neovasculopathy (PNV) and polypoidal choroidal vasculopathy (PCV). Compared to controls, no significant upregulation of IL-6 levels were found in both the pooled result nor subgroup analyses (Fig. 7B). No publication bias was identified (Supplemental Fig. S7D, Supplemental Table S4).

\section{Discussion}

To date, this study is the first and most comprehensive meta-analysis on the role of IL-6-174 G/C polymorphism and IL-6 levels in the pathogenesis of ophthalmic diseases. The pooled analyses revealed that IL-6-174 G/C polymorphism was not associated with the ocular diseases in any inheritance models, despite increased intraocular and tear IL-6 levels. The first important notion is that the GC genotype of IL-6-174 G/C is marginally associated with PDR. Previous studies have described that the CC genotype has a trend toward a higher frequency of $\mathrm{DR}^{236}$, while the prevalence of metabolic syndrome is correlated with the $\mathrm{C}+$ carrier individuals ${ }^{237}$. Despite extensive characterization of IL-6 promoter polymorphisms, conflicting results are still observed in 


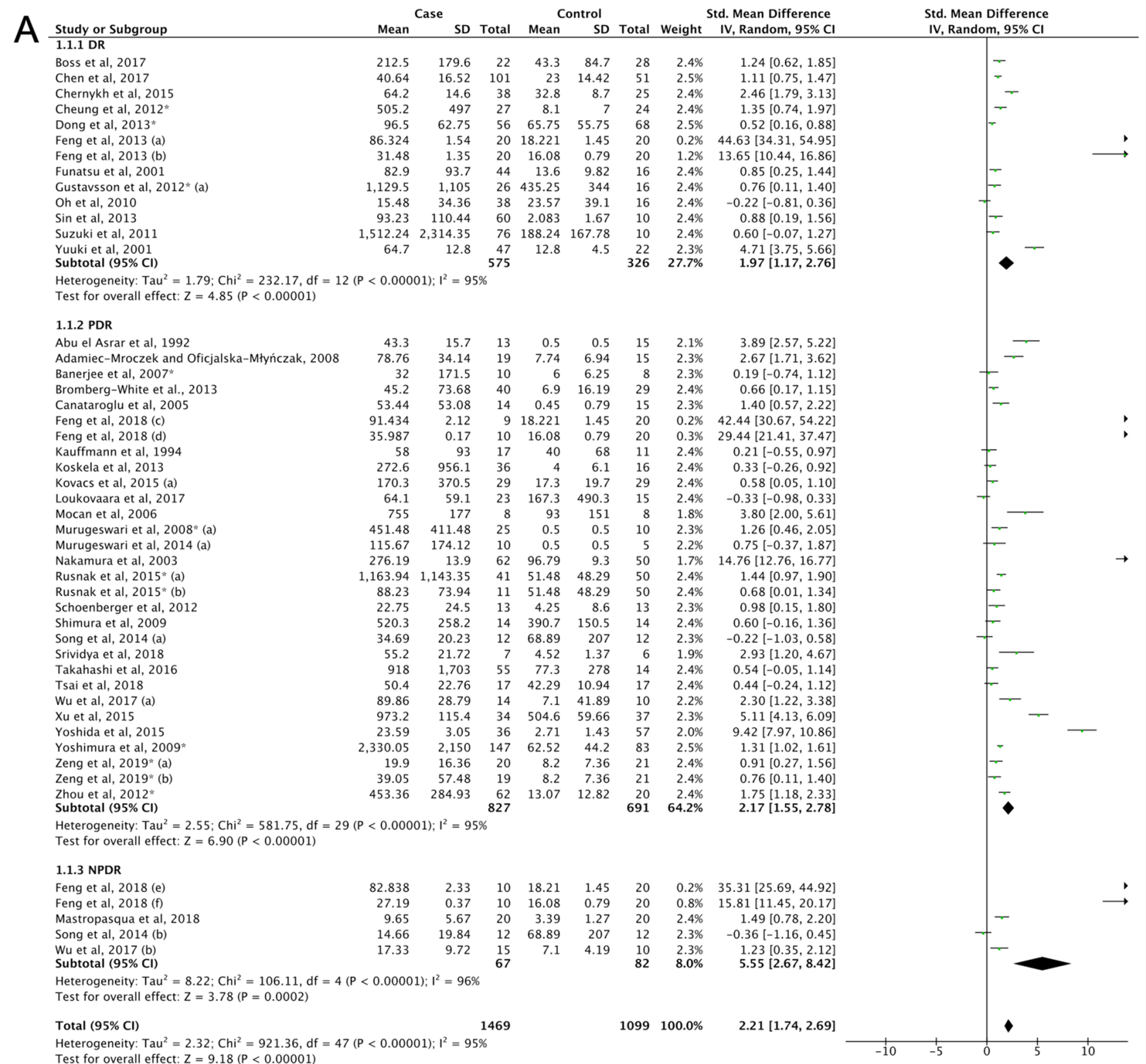

B

Test for overall effect: $Z=9.18(\mathrm{P}<0.00001)$

Test for subgroup differences: $\mathrm{Chi}^{2}=5.54, \mathrm{df}=2(\mathrm{P}=0.06), \mathrm{I}^{2}=63.9 \%$

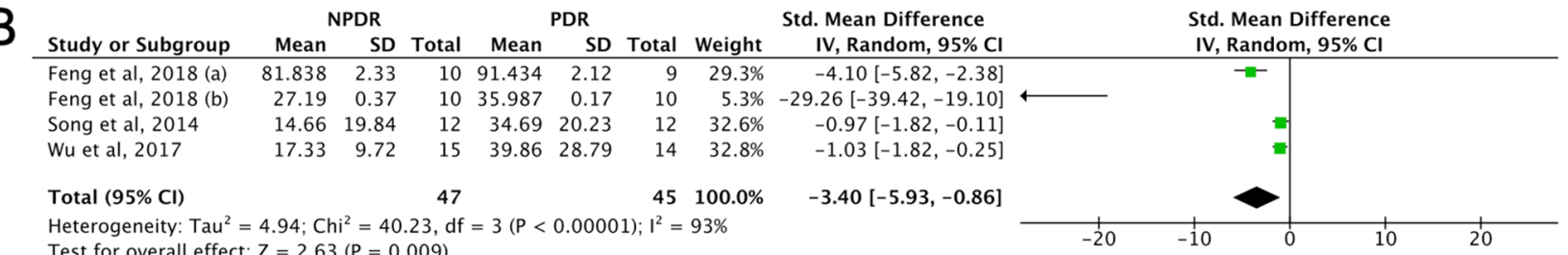

Figure 4. (A) Forest plot for pooled SMD and 95\% CI for IL-6 levels between DR and control; (B) Forest plot for pooled SMD and 95\% CI for IL-6 levels between the NPDR and PDR.

varying populations and diseases. Several studies reported the IL-6-174C allele is associated with higher IL-6 serum concentrations ${ }^{238,239}$, while others state the opposite ${ }^{13,14}$. Despite this discrepancy, individuals with CC genotype exhibit a high body mass index (BMI) and risk of developing type 2 diabetes mellitus (T2DM) ${ }^{240}$. Additionally, a positive correlation between IL-6 levels and insulin resistance (IR) has also been observed in the $\mathrm{C}+$ diabetic carriers ${ }^{241}$. Thus, this study strengthens the notion that IL-6-174C allele may be associated with the risk of developing DR.

The second important observation is that in parallel with GC genotype as a risk factor of PDR development, intraocular IL-6 level was also two-fold higher in DR patients. More importantly, the pooled result revealed that intraocular IL-6 level was higher in the PDR group compared to NPDR, which is in line with previously 


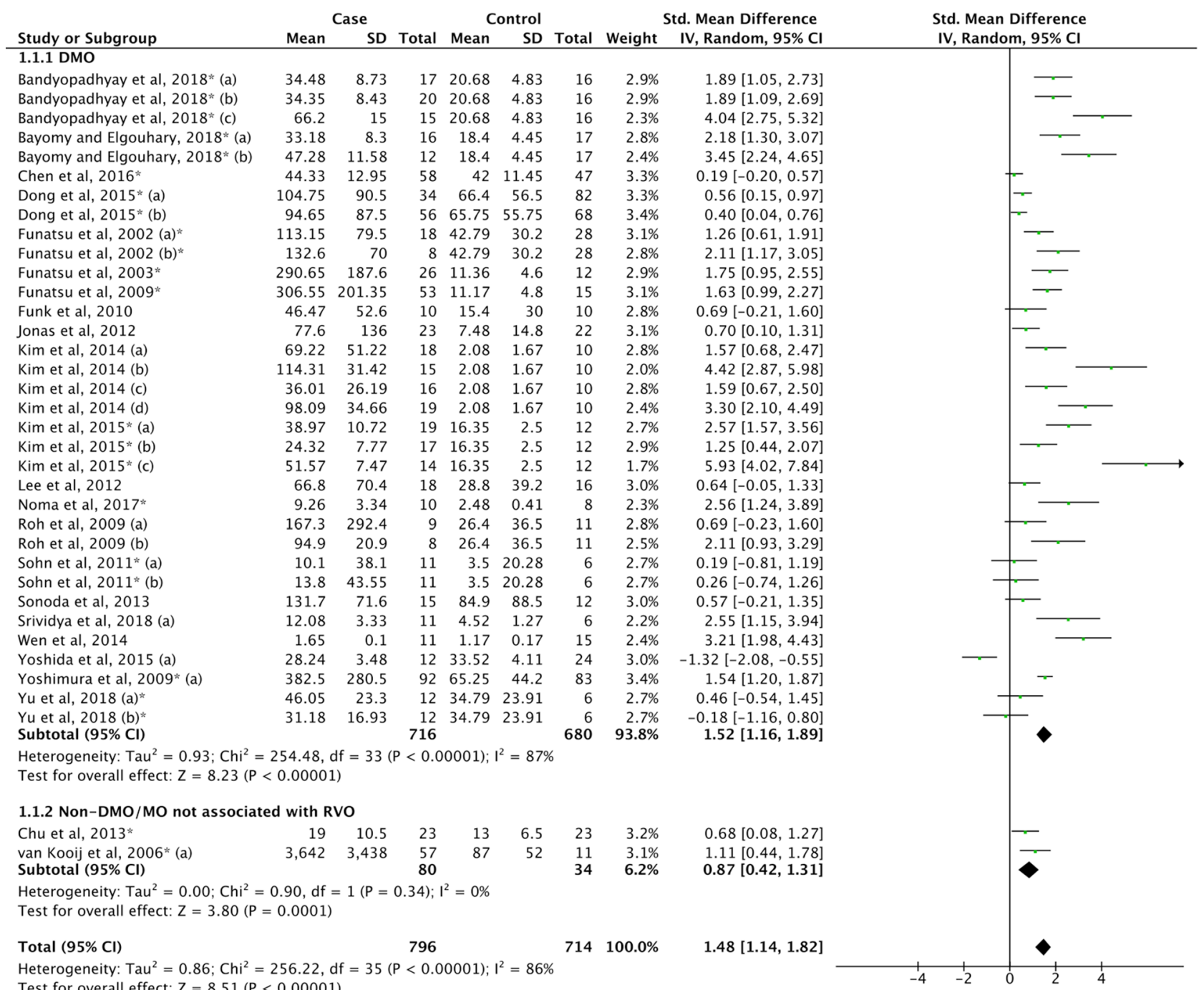

Figure 5. Forest plot for pooled SMD and 95\% CI for IL-6 levels between MO and control.

conducted studies ${ }^{234}$. The upregulation of IL-6 as an upstream transcriptional regulator of inflammation has been detected in the retina of a diabetic mode ${ }^{242}$. It has been reported that the IL-6 knockout $(\mathrm{KO})$ mice inhibit leukocyte infiltration to the retinal vessels and vascular leakage by $75 \%$ in the diabetic model ${ }^{243}$. The level of IL-6 has been reported linearly associated with an increase of neovascularization activity in PDR ${ }^{244}$. Moreover, a cross-sectional study confirmed a relationship between IR and severity of retinopathy in diabetic patients ${ }^{245}$. Together, these results imply that IL-6 might be critical in mediating insulin-induced vascular remodelling.

Our study demonstrated that higher levels of IL- 6 were associated with the overall risk of ocular diseases $(\mathrm{SMD}=1.41,95 \%$ CI 1.24-1.58, $\mathrm{P}<0.00001)$. Moreover, high concentrations of IL-6 were found specifically in several ocular diseases, such as secondary glaucoma, PEX syndrome, surface ocular and intraocular inflammation, MO, CRVO, BRVO, PVR, ROP and RD, but not to POAG, PACG, AMD, CNV, asymptomatic CL users, pachychoroid spectrum diseases, ERM, cataract, pseudophakia and PBK (summarized in Fig. 8). Our analysis indicate that the upregulation of IL-6 levels in these specific ocular diseases are not necessarily associated with IL-6-174 G/C (rs1800795) polymorphism, therefore implying the potential modulating roles of other single nucleotide polymorphisms (SNPs) in the promoter region of IL-6. In fact, several studies have shown associations between rs1800796, rs1800797, and rs1524107, with surface ocular diseases and glaucoma ${ }^{27,246,247}$. Therefore, it may be useful for future studies to investigate the relationship between IL- 6 genetic variants with intraocular IL-6 levels in ophthalmic cases, because it may provide more insight into the specific role of IL-6 in the ocular disease and provide more clarity or precision to the association.

The IL-6 levels tend to be high in glaucoma. However, only secondary glaucoma exhibited significantly increased IL-6 levels in this analysis, and no evidence of increase was found in POAG or PACG. This is possibly due to secondary glaucoma being caused by underlying diseases that are associated with a high IL-6 level, including PEX syndrome, intraocular inflammation, $\mathrm{DR}, \mathrm{ROP}$ and $\mathrm{RD}^{248}$. And in regard to the lack of IL-6 increase in primary glaucoma, it is interesting to note previous reports showing that soluble IL-6 receptor (sIL-6R) but not IL-6 is elevated in the aqueous humour of POAG ${ }^{49}$. This interaction between IL- 6 and sIL6R is known to 


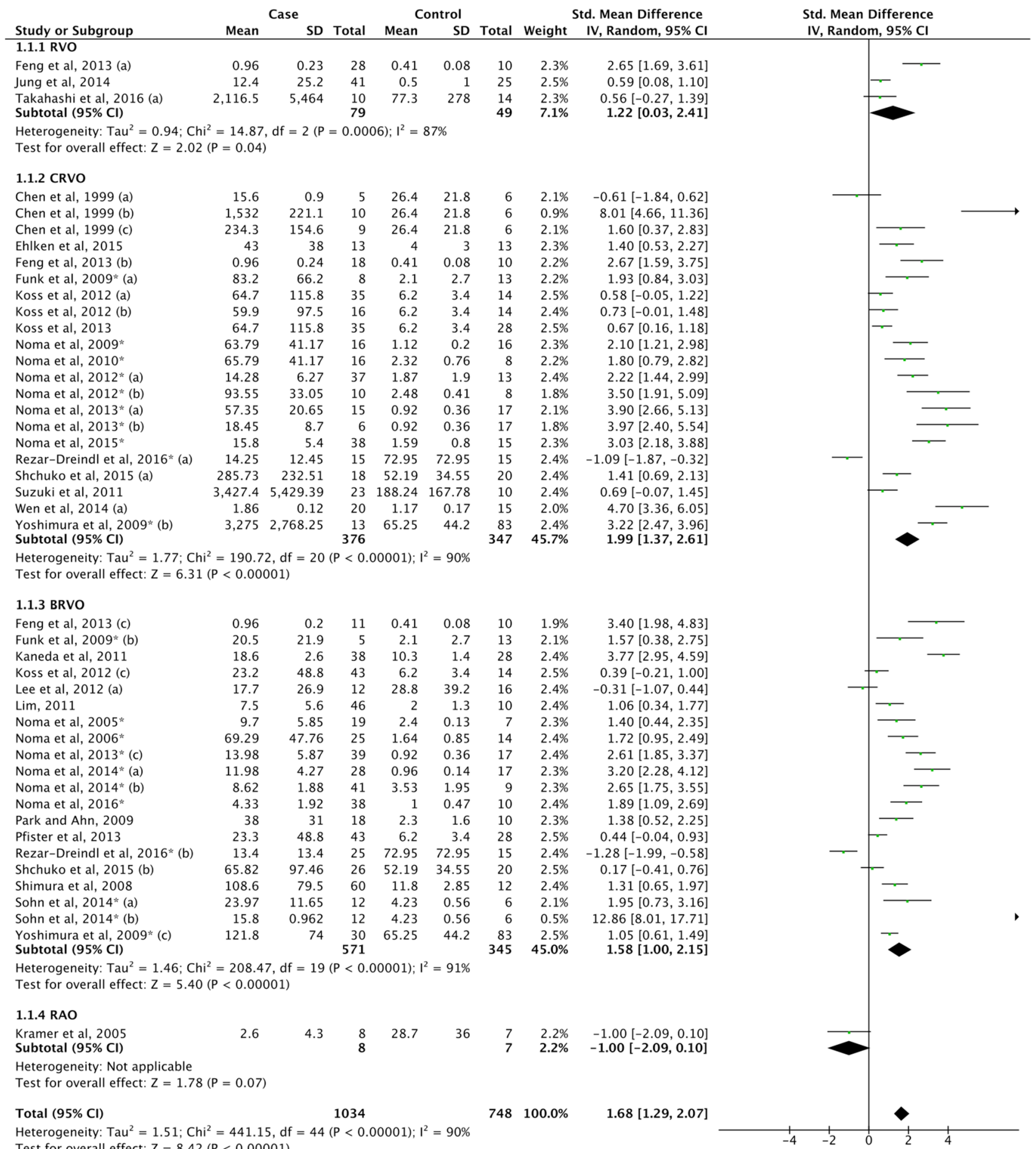

Figure 6. Forest plot for pooled SMD and 95\% CI for IL-6 levels between retinal vascular occlusion and control.

exhibit the inhibitory action of TGF- $\beta$-induced up-regulation of fibrotic changes in vitro ${ }^{49}$, suggesting that transsignalling of IL- 6 could be a potential target of POAG treatment. Despite the fact that IL-6 may not directly contribute to OAG pathogenesis, studies confirmed an elevated level of TNFa and IL-8 in the OAG eye $\mathrm{e}^{249,250}$, which emphasizes that the inflammatory process is involved in the OAG progression.

Although both CRVO and BRVO groups displayed high intraocular IL-6 levels, the increase was higher in CRVO than BRVO. Previous studies measuring other parameters such as ischaemic index and aqueous vascular endothelial growth factor concentration, also showed higher results in CRVO compared to BRVO ${ }^{251,252}$, thereby implicating the presence of more aggressive pathogenesis in CRVO. In terms of IL-6 involvement in RVO, IL-6 expression was found to be essential in modulating vascular inflammation through the upregulation of retinal 


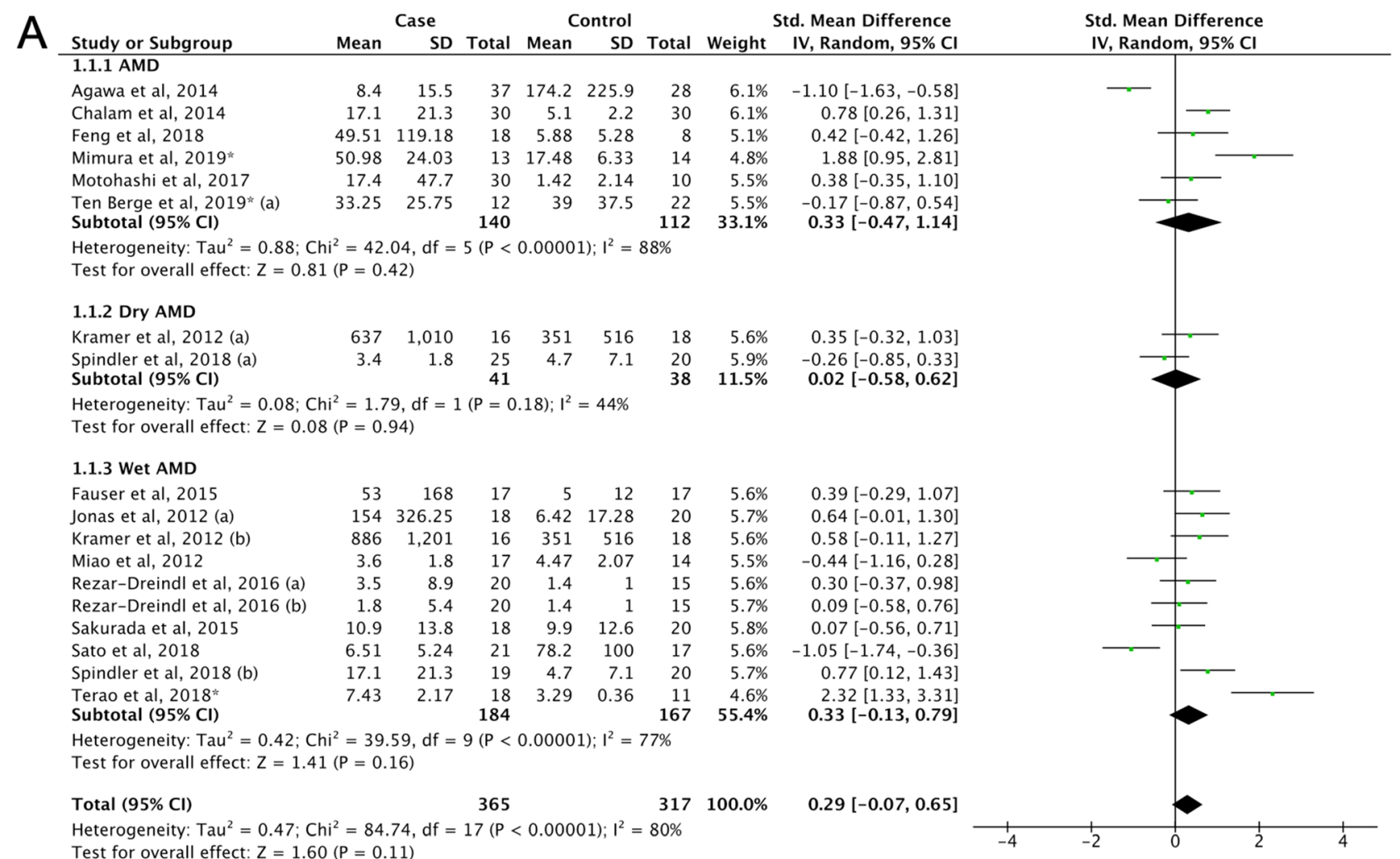

B

\begin{tabular}{|c|c|c|c|c|c|c|c|c|c|}
\hline \multirow{3}{*}{$\begin{array}{l}\text { Study or Subgroup } \\
1.1 .1 \text { CSC }\end{array}$} & \multicolumn{2}{|c|}{ Case } & \multicolumn{4}{|c|}{ Control } & \multicolumn{2}{|r|}{ Std. Mean Difference } & \multirow{2}{*}{$\begin{array}{l}\text { Std. Mean Difference } \\
\text { IV, Random, } 95 \% \mathrm{CI}\end{array}$} \\
\hline & Mean & SD & Total & Mean & SD & Total & Weight & IV, Random, 95\% CI & \\
\hline & & & & & & & & & \\
\hline Jung et al, 2014 & 0.32 & 0.79 & 39 & 0.46 & 0.59 & 25 & $17.1 \%$ & $-0.19[-0.70,0.31]$ & \\
\hline $\begin{array}{l}\text { Shin and } \operatorname{Lim}, 2011 \\
\text { Subtotal }(95 \% \mathrm{Cl})\end{array}$ & 1.6 & 0.5 & $\begin{array}{l}20 \\
59\end{array}$ & 2.1 & 1.4 & $\begin{array}{l}20 \\
45\end{array}$ & $\begin{array}{l}13.0 \% \\
30.2 \%\end{array}$ & $\begin{array}{l}-0.47[-1.10,0.16] \\
-0.30[-0.69,0.09]\end{array}$ & \\
\hline \multicolumn{10}{|c|}{$\begin{array}{l}\text { Heterogeneity: } \mathrm{Tau}^{2}=0.00 ; \mathrm{Chi}^{2}=0.44, \mathrm{df}=1(\mathrm{P}=0.51) ; \mathrm{I}^{2}=0 \% \\
\text { Test for overall effect: } \mathrm{Z}=1.49(\mathrm{P}=0.14)\end{array}$} \\
\hline \multicolumn{10}{|l|}{ 1.1.2 PNV } \\
\hline Feng et al, 2018 & 191.14 & 315.93 & 7 & 70.71 & 92.5 & 8 & $6.1 \%$ & $0.50[-0.53,1.54]$ & \\
\hline $\begin{array}{l}\text { Terao et al, } 2018^{*} \\
\text { Subtotal }(\mathbf{9 5 \%} \mathbf{C l})\end{array}$ & 4.71 & 2.72 & $\begin{array}{l}18 \\
25\end{array}$ & 3.29 & 0.36 & $\begin{array}{l}11 \\
19\end{array}$ & $\begin{array}{r}9.8 \% \\
15.9 \%\end{array}$ & $\begin{array}{l}0.64[-0.13,1.41] \\
0.59[-0.03,1.21]\end{array}$ & \\
\hline \multicolumn{10}{|c|}{$\begin{array}{l}\text { Heterogeneity: } \mathrm{Tau}^{2}=0.00 ; \mathrm{Chi}^{2}=0.04, \mathrm{df}=1(\mathrm{P}=0.84) ; \mathrm{I}^{2}=0 \% \\
\text { Test for overall effect: } \mathrm{Z}=1.87(\mathrm{P}=0.06)\end{array}$} \\
\hline \multicolumn{10}{|l|}{ 1.1.3 PCV } \\
\hline Hu et al, 2016 (a) & 8.59 & 12.94 & 41 & 10.02 & 8.93 & 44 & $20.4 \%$ & $-0.13[-0.55,0.30]$ & \\
\hline Hu et al, 2016 (b) & 5.74 & 7.77 & 39 & 10.02 & 8.93 & 44 & $19.8 \%$ & $-0.50[-0.94,-0.07]$ & - \\
\hline $\begin{array}{l}\text { Sakurada et al, } 2015 \\
\text { Subtotal }(95 \% \mathrm{Cl})\end{array}$ & 13 & 43.3 & $\begin{array}{r}22 \\
102\end{array}$ & 9.9 & 12.6 & $\begin{array}{r}20 \\
108\end{array}$ & $\begin{array}{l}13.7 \% \\
53.9 \%\end{array}$ & $\begin{array}{r}0.09[-0.51,0.70] \\
-0.22[-0.55,0.11]\end{array}$ & \\
\hline \multicolumn{10}{|c|}{$\begin{array}{l}\text { Heterogeneity: } \mathrm{Tau}^{2}=0.02 ; \mathrm{Chi}^{2}=2.82, \mathrm{df}=2(\mathrm{P}=0.24) ; \mathrm{I}^{2}=29 \% \\
\text { Test for overall effect: } Z=1.30(\mathrm{P}=0.19)\end{array}$} \\
\hline Total $(95 \% \mathrm{Cl})$ & & & 186 & & & 172 & $100.0 \%$ & $-0.11[-0.39,0.16]$ & \\
\hline \multicolumn{9}{|c|}{ Heterogeneity: $\mathrm{Tau}^{2}=0.05 ; \mathrm{Chi}^{2}=9.67, \mathrm{df}=6(\mathrm{P}=0.14) ; \mathrm{I}^{2}=38 \%$} & $\begin{array}{c}1 \\
-2\end{array}$ \\
\hline
\end{tabular}

Test for overall effect: $\mathrm{Z}=0.81(\mathrm{P}=0.42)$

Test for subgroup differences: $\mathrm{Chi}^{2}=6.18, \mathrm{df}=2(\mathrm{P}=0.05), \mathrm{I}^{2}=67.6 \%$

Figure 7. (A) Forest plot for pooled SMD and 95\% CI for IL-6 levels between AMD and control; (B) Forest plot for pooled SMD and 95\% CI for IL-6 levels between pachychoroid spectrum diseases and control.

vascular endothelial growth factor (VEGF $)^{253}$, indicating an indirect role towards increased endothelial permeability via VEGF. Thus, as a consequence, the prognosis of CRVO is less favourable than BRVO. Nonetheless, further detail on the interaction between IL-6-VEGF and its implication on the initiation of retinal vascular disease requires more investigation.

Intraocular inflammation in this study was mainly focused on uveitis. For the analysis, studies evaluating intraocular IL-6 levels from uveitis patients were classified based on the aetiology ${ }^{254}$. Regardless of aetiology, this report clearly demonstrated that intraocular IL-6 levels were significantly increased in uveitis. Although a 


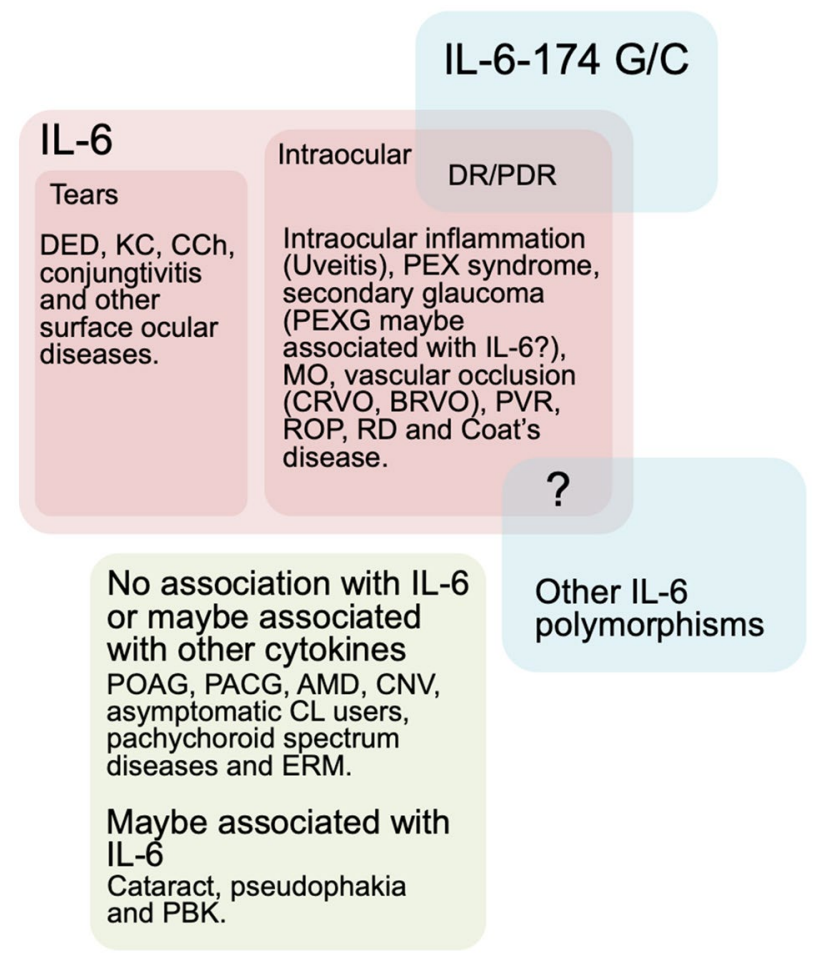

Figure 8. Summary of meta-analysis between IL-6 and ophthalmic diseases. AMD age-related macular degeneration, $B R V O$ branch retinal vein occlusion, $C C h$ conjunctivochalasis, $C L$ contact lens, $C N V$ choroidal neovascularization, $C R V O$ central retinal vein occlusion, $K C$ keratoconus, $M O$ macular oedema, $D R$ diabetic retinopathy, ERM epiretinal membrane, $P A C G$ primary angle-closure glaucoma, $P B K$ pseudophakic bullous keratopathy, $P D R$ proliferative diabetic retinopathy, $P E X$ pseudoexfoliation syndrome, $P O A G$ primary openangle glaucoma, $P V R$ proliferative vitreoretinopathy, $R D$ retinal detachment, $R O P$ retinopathy of prematurity, $R P$ retinitis pigmentosa.

majority of previous investigations have shown higher serum IL-6 levels among uveitis patients than healthy controls, results of ocular fluid observations are less consistent ${ }^{255,256}$. In addition to the intraocular IL-6 levels, it was also confirmed that tear levels of IL-6 was higher among surface ocular diseases, including conjunctivitis, dry eye disease (DED), keratoconus (KC) and keratitis. Hence, this reflects that inhibition of local immune reaction during active inflammation may be critical for the management of ocular inflammation diseases.

Macular oedema is a leading cause of vision loss and represents an important clinical and public health problem. MO encompasses a pathological condition with intra- or subretinal fluid accumulation in the central retina $^{257}$. Although a variety of pathological conditions could lead to the development of MO, this article will focus on the three main causes: DR, RVO and uveitis. The exact mechanisms of MO remain unclear, but one possible explanation is the involvement of the inflammatory process which has been considered critical towards increasing vascular permeability and subsequent breakdown of the blood-retinal barrier (BRB) ${ }^{258,259}$. In this study, intraocular levels of IL-6 was significantly higher in DMO than non-DMO/RVO. On closer examination, it was found that patients with MO secondary to CRVO or BRVO showed a higher IL-6 concentration than patients with CRVO or BRVO alone. Indeed, the administration of IL-6 disrupts the integrity of human retinal pigment epithelial cells (ARPE-19) leading to increased cellular permeability concomitant with a low trans endothelial electrical resistance (TEER) ${ }^{260}$. This indicates the potential use of IL- 6 as a biomarker and therapeutic target of retinal vascular diseases. To date, several studies and clinical trials utilizing the human anti-IL-6R antibody (Tocilizumab and Sarilumab) for ocular diseases have been introduced ${ }^{261-267}$. A phase II clinical trial for Tocilizumab (clinicaltrials.gov identifier NCT03554161) in the treatment of refractory Behcet's uveitis is also enrolling patients. Together, both treatments have shown clinical benefit in the management of non-infectious uveitis and refractory uveitis-related $\mathrm{MO}$.

Although the number of pooled studies were relatively small, increased IL-6 level was also observed in RD, PVR, ROP and Coats' disease. All these conditions share common similarity in terms of subretinal fluid accumulation. The possible role of IL-6 lies in its ability to promote vascular leakage in the retina, which may further escalate the inflammatory response within the eye. An interesting finding has indicated that trans-signalling IL-6 pathways predominantly occur in the ocular fluid of the RD model ${ }^{268}$. Other studies have confirmed significantly higher IL-6 concentration in the PVR than RD eye ${ }^{269,270}$. Overall, these results support the findings of this study, confirming the important role of IL- 6 in the progression and severity of ocular diseases.

There was no evidence of IL-6 upregulation in AMD, CNV and pachychoroid spectrum diseases. However, IL-8 + $781 \mathrm{C} / \mathrm{T}$ (rs2227306) polymorphism in parallel with elevated IL-8 levels were associated with wet AMD ${ }^{271}$. 
Intraocular concentrations of IL- 6 and IL-8 have been reported to be closely associated with the volume of MO and size of active CNV ${ }^{175,182}$. Moreover, IL- 6 and IL- 8 are significantly upregulated in the chronic CSC group compared with the acute CSC or PNV groups ${ }^{272}$. Therefore, further studies are needed to elucidate the role of IL-6 in the aetiology of AMD, CNV and pachychoroid spectrum diseases.

The strength of this study is on the large number of eligible studies collected for the meta-analysis, deeming the results presented as more conclusive. Thus, IL- 6 should be considered as a promising marker and alternative approach to determine the presence of ophthalmic disorders. However, the analysis performed on several ocular disease subgroups used relatively small sizes, and so further studies are still needed to confirm these results. Several limitations of this study includes the limited availability of published papers on IL-6 polymorphism, which may lessen the precision of the effect estimate. Secondly, since ocular disease aetiology are multifactorial, other factors including genetic, hormonal, and environmental status need to be examined. Considering the above-mentioned limitations, these findings should be interpreted with caution.

In summary, this present meta-analysis suggests that IL-6-174 G/C polymorphism does not predispose patients to the ocular disease, but the intraocular IL-6 concentrations are related to the specific manifestations of the ophthalmic diseases. Another important point to note is that the GC genotype of IL-6-174 G/C polymorphism may serve as a potential biomarker of PDR. However, due to the complexity of PDR aetiologies and pathogenesis, multi-modality assessments combining genetic analysis with retinal imaging as well as non-genetic predispositions and other related biomarkers need to be performed in order to evaluate the risk and progression of DR. Overall, this study supports the notion that IL-6 plays a pivotal role in the pathogenesis of ophthalmic disorders. It is expected that more studies will become available to verify this conclusion.

\section{Methods}

Search strategy and study selection. The current meta-analysis was performed according to the Preferred Reporting Items for Systematic Reviews and Meta-Analysis (PRISMA) guideline ${ }^{273}$. A literature search was conducted from PubMed, Scopus and Web of Science databases up to October 2019 using the following keywords or terms, and their combination such as "IL-6 or interleukin-6", "IL-6-174 G/C", "cytokine", "inflammation", "polymorphism" and "eye disease/ophthalmology". No language restrictions were imposed. In addition, reference lists of retrieved articles were manually screened to identify additional or potentially missing eligible studies. Studies were included based on fulfilment of the following criteria: (1) case-control study evaluating the association of IL-6-174 G/C or intraocular IL-6 levels with ocular disease; (2) genotype or allele frequencies or distributions in both case and control groups were provided; (3) IL-6 levels were quantified from aqueous or vitreous humour samples utilising ELISA (enzyme-linked immunosorbent assay) or multiplex bead immunoassay or immunoarray. If the level of IL- 6 was not presented as mean and standard deviation (SD), estimated values were calculated as a previously described ${ }^{274,275}$. Animal studies, case reports, reviews, abstracts and incomplete studies were excluded. Two investigators (Z.U. and G.S.) independently selected the studies for final inclusion on the basis of these criteria. Disagreements between the two investigators were resolved and achieved after further discussion with the other investigators (B and L.W.)

Data extraction. Data were extracted as follows: (1) name of the first author; (2) year of publication; (3) country of origin; (4) number of cases and controls; (5) age; (6) number of genotypes in cases and controls and (7) IL-6 levels in aqueous or vitreous humour from cases and controls.

Data synthesis and analysis. Meta-analysis for IL-6 gene polymorphism was performed for two or more studies. Genotypic frequency of IL-6 gene polymorphism was tested for deviation from the Hardy-Weinberg equilibrium (HWE) in the control subjects. The genetic association was assessed using different genetic models, including allelic (a vs. A), recessive (aa vs. Aa + AA), dominant (aa + Aa vs. AA), over dominant (Aa vs. aa + AA), homozygous (aa vs. AA), heterozygous (Aa vs. AA), and Aa vs. aa models. The association between IL-6-174 G/C polymorphism with the ocular disease was calculated by the pooled OR and $95 \%$ CI. Z test was assessed to evaluate the significance of the pooled effect size. Heterogeneity among studies was evaluated using Q test and $\mathrm{I}^{2}$ statistic. A significant $\mathrm{Q}$-statistic $(\mathrm{P}<0.10)$ indicated heterogeneity across studies. The $\mathrm{I}^{2}$ values indicated no (0-24.9\%), low (25-49.9\%), moderate (50-74.9\%) or high (75-100\%) heterogeneity. The random-effect model (REM) was used if heterogeneity existed; otherwise, the fixed-effect model (FEM) was used ${ }^{250,276-287}$. Subgroup analysis was stratified by type of disease and ethnicity or racial descent.

Meta-analysis to evaluate IL-6 levels in the ocular disease was performed by REM to allow heterogeneity. Pooled SMD with 95\% CI was used to assess the IL-6 levels between the patients with ocular disease and the controls. Subgroup and meta-regression analyses were also performed to investigate potential sources of heterogeneity. A sensitivity test was performed by sequentially omitting one study each time to evaluate the stability of the results. Begg's funnel plots and Egger's regression test were used to investigate the publication bias within studies. When a publication bias was detected, trim and fill analysis was performed to assess the number of missing studies. The Newcastle-Ottawa Scale (NOS) was utilised to assess the quality of case-control studies ${ }^{288}$ (Supplemental Table S9), with a maximum score of 9 for each study. A study scoring than 5 was judged at a high risk of bias ${ }^{289}$. All analyses were performed using MetaGenyo ${ }^{290}$, RevMan ver 5.3, Meta-Essential 1.4291, and Open Meta-Analyst ${ }^{292}$. Statistical tests were 2-sided and used a significance threshold of $\mathrm{p}<0.05$.

Data availability

All data generated or analysed are included in this article. 
Received: 24 January 2020; Accepted: 26 September 2020

Published online: 15 October 2020

\section{References}

1. Zhang, J. et al. Pathogenesis of common ocular diseases. J. Ophthalmol. 2015, (2015).

2. Freire, M. O. \& Van Dyke, T. E. Natural resolution of inflammation. Periodontology 2000(63), 149-164 (2013).

3. Hessen, M. \& Akpek, E. K. Dry eye: An inflammatory ocular disease. J Ophthalmic Vis. Res. 9, 240-250 (2014).

4. Yeung, I. Y., Popp, N. A. \& Chan, C.-C. The role of gender in uveitis and ocular inflammation. Int. Ophthalmol. Clin. 55, 111-131 (2015).

5. Turner, M. D., Nedjai, B., Hurst, T. \& Pennington, D. J. Cytokines and chemokines: At the crossroads of cell signalling and inflammatory disease. Biochim. Biophys. Acta. 1843, 2563-2582 (2014).

6. Zahir-Jouzdani, F., Atyabi, F. \& Mojtabavi, N. Interleukin-6 participation in pathology of ocular diseases. Pathophysiology 24, 123-131 (2017)

7. Tanaka, T., Narazaki, M. \& Kishimoto, T. IL-6 in inflammation, immunity, and disease. Cold Spring Harb. Perspect. Biol. 6, a016295 (2014)

8. Jones, S. A., Horiuchi, S., Topley, N., Yamamoto, N. \& Fuller, G. M. The soluble interleukin 6 receptor: Mechanisms of production and implications in disease. FASEB J. 15, 43-58 (2001).

9. Luo, Y. \& Zheng, S. G. Hall of fame among pro-inflammatory cytokines: Interleukin-6 gene and its transcriptional regulation mechanisms. Front. Immunol. 7, 604 (2016).

10. Fishman, D. et al. The effect of novel polymorphisms in the interleukin-6 (IL-6) gene on IL-6 transcription and plasma IL-6 levels, and an association with systemic-onset juvenile chronic arthritis. J. Clin. Invest. 102, 1369-1376 (1998).

11. Fernández-Real, J. M., Broch, M., Vendrell, J., Richart, C. \& Ricart, W. Interleukin-6 gene polymorphism and lipid abnormalities in healthy subjects. J. Clin. Endocrinol. Metab. 85, 1334-1339 (2000).

12. Terry, C. F., Loukaci, V. \& Green, F. R. Cooperative influence of genetic polymorphisms on interleukin 6 transcriptional regulation. J. Biol. Chem. 275, 18138-18144 (2000).

13. Hulkkonen, J., Pertovaara, M., Antonen, J., Pasternack, A. \& Hurme, M. Elevated interleukin- 6 plasma levels are regulated by the promoter region polymorphism of the IL6 gene in primary Sjögren's syndrome and correlate with the clinical manifestations of the disease. Rheumatology (Oxford) 40, 656-661 (2001).

14. Bennermo, M. et al. Genetic predisposition of the interleukin-6 response to inflammation: Implications for a variety of major diseases?. Clin. Chem. 50, 2136-2140 (2004).

15. Lin, K.-H. et al. Interleukin-6(-174) locus polymorphism and serum IL-6 levels in normal tension glaucoma. Ophthalmic Genet. 35, 255-257 (2014).

16. Wang, C.-Y. et al. Analysis of the interleukin-6 (-174) locus polymorphism and serum il-6 levels with the severity of normal tension glaucoma. Ophthalmic Res. 57, 224-229 (2017).

17. Wu, L., Chen, Z., Huang, G. \& Lu, X. Association between IL-6 genetic polymorphisms and primary open-angle glaucoma risk in Chinese population. Int. J. Clin. Exp. Med. 9, 9539-9544 (2016).

18. Zimmermann, C., Weger, M., Faschinger, C., Renner, W. \& Mossböck, G. Role of interleukin 6-174G $>$ C polymorphism in primary open-angle glaucoma. Eur. J. Ophthalmol. 23, 183-186 (2013).

19. Goverdhan, S. V. et al. Interleukin-8 promoter polymorphism $-251 \mathrm{~A} / \mathrm{T}$ is a risk factor for age-related macular degeneration. $B r$. J. Ophthalmol. 92, 537-540 (2008).

20. Lu, Q.-K. et al. Association of il-6 gene (-174 and $-572 \mathrm{~g} / \mathrm{c}$ ) polymorphisms with proliferative diabetic retinopathy of type 2 diabetes in a Chinese population. Ophthalmic Res. 58, 162-167 (2017).

21. Masood, I., Negi, A., Vernon, S. A., Comeglio, P. \& Child, A. H. The -174G/C interleukin-6 promoter polymorphism influences the development of macular oedema following uncomplicated phacoemulsification surgery. Eye (Lond.) 21, 1412-1415 (2007).

22. Myśliwska, J. et al. The -174GG interleukin-6 genotype is protective from retinopathy and nephropathy in juvenile onset type 1 diabetes mellitus. Pediatr. Res. 66, 341-345 (2009).

23. Paine, S. K. et al. Association of tumor necrosis factor $\alpha$, interleukin 6 , and interleukin 10 promoter polymorphism with proliferative diabetic retinopathy in type 2 diabetic subjects. Retina (Philadelphia, Pa.) 32, 1197-1203 (2012).

24. Ruiz-Colmenares, M. R. S., Jimeno, J. C. P., Adrados, J. A. G., Orriols, J. J. T. \& Fernández, M. I. Y. Cytokine gene polymorphisms in retinal detachment patients with and without proliferative vitreoretinopathy: A preliminary study. Acta Ophthalmol. Scand. 84, 309-313 (2006).

25. Anvari, M. et al. Genetic susceptibility to Graves' ophthalmopathy: The role of polymorphisms in proinflammatory cytokine genes. Eye (Lond.) 24, 1058-1063 (2010).

26. Bednarczuk, T. et al. Association of G-174C polymorphism of the interleukin-6 gene promoter with Graves' ophthalmopathy. Autoimmunity 37, 223-226 (2004)

27. Carnt, N. A. et al. Association of single nucleotide polymorphisms of interleukins- $1 \beta$, -6 , and $-12 \mathrm{~B}$ with contact lens keratitis susceptibility and severity. Ophthalmology 119, 1320-1327 (2012).

28. Cordeiro, C. A. et al. Interleukin-6 gene polymorphism $(-174 \mathrm{G} / \mathrm{C})$ is associated with toxoplasmic retinochoroiditis. Acta Ophthalmol. 91, e311-314 (2013).

29. Dilek, K. et al. Cytokine gene polymorphisms in Behçet's disease and their association with clinical and laboratory findings. Clin. Exp. Rheumatol. 27, S73-78 (2009).

30. Ewald, L., Beate, L.-W., Stephanie, S., Wilfried, R. \& Yosuf, E.-S. Analysis of a functional il-6 gene polymorphism in hlab27 associated and intermediate uveitis gives new insight in disease pathogenesis and commonality with other autoimmune diseases. J. Immunol. Res 2015, 174062 (2015).

31. Gedvilaite, G., Vilkeviciute, A., Kriauciuniene, L., Asmoniene, V. \& Liutkeviciene, R. Does CETP rs5882, rs708272, SIRT1 rs12778366, FGFR2 rs2981582, STAT3 rs744166, VEGFA rs833068, IL6 rs1800795 polymorphisms play a role in optic neuritis development?. Ophthalmic Genet 40, 219-226 (2019).

32. Na, K.-S., Mok, J.-W., Kim, J. Y. \& Joo, C.-K. Proinflammatory gene polymorphisms are potentially associated with Korean non-Sjogren dry eye patients. Mol. Vis. 17, 2818-2823 (2011).

33. Sen, A. et al. Impact of interleukin-6 promoter polymorphism and serum interleukin- 6 level on the acute inflammation and neovascularization stages of patients with Eales' disease. Mo. Vis. 17, 2552-2563 (2011).

34. Talaat, R. M., Ashour, M. E., Bassyouni, I. H. \& Raouf, A. A. Polymorphisms of interleukin 6 and interleukin 10 in Egyptian people with Behcet's disease. Immunobiology 219, 573-582 (2014).

35. Steinbrugger, I. et al. Analysis of inflammation- and atherosclerosis-related gene polymorphisms in branch retinal vein occlusion. Mol. Vis. 15, 609-618 (2009).

36. Weger, M. et al. Role of the interleukin-6-174 G>C gene polymorphism in retinal artery occlusion. Stroke 36, 249-252 (2005).

37. Kucherenko, A. M., Pampukha, V. M., Drozhzhyna, G. I. \& Livshits, L. A. ILlbeta, IL6 and IL8 gene polymorphisms involvement in recurrent corneal erosion in patients with hereditary stromal corneal dystrophies. Tsitol. Genet. 47, 42-45 (2013).

38. Liton, P. B. et al. Induction of IL-6 expression by mechanical stress in the trabecular meshwork. Biochem. Biophys. Res. Commun. 337, 1229-1236 (2005). 
39. Sato, K. et al. Interleukin-6 plays a crucial role in the development of subretinal fibrosis in a mouse model. Immunol. Med. 41, 23-29 (2018).

40. Yoon, K.-C., Jeong, I.-Y., Park, Y.-G. \& Yang, S.-Y. Interleukin-6 and tumor necrosis factor-alpha levels in tears of patients with dry eye syndrome. Cornea 26, 431-437 (2007).

41. Valentincic, N. V. et al. Intraocular and serum cytokine profiles in patients with intermediate uveitis. Mol. Vis. 17, 2003-2010 (2011).

42. Noma, H., Funatsu, H., Mimura, T., Harino, S. \& Hori, S. Vitreous levels of interleukin-6 and vascular endothelial growth factor in macular edema with central retinal vein occlusion. Ophthalmology 116, 87-93 (2009).

43. Ghanem, A. A., Arafa, L. F. \& Elewa, A. Tumor necrosis factor- $\alpha$ and interleukin-6 levels in patients with primary open-angle glaucoma. J. Clin. Exp. Ophthalmol. 2, 118 (2011).

44. Chen, K. H., Wu, C. C., Roy, S., Lee, S. M. \& Liu, J. H. Increased interleukin-6 in aqueous humor of neovascular glaucoma. Invest. Ophthalmol. Vis. Sci. 40, 2627-2632 (1999).

45. Borkenstein, A. et al. Measurement of tumor necrosis factor-alpha, interleukin-6, Fas ligand, interleukin-1 $\alpha$, and interleukin- $1 \beta$ in the aqueous humor of patients with open angle glaucoma using multiplex bead analysis. Mol. Vis. 19, 2306-2311 (2013).

46. Chua, J. et al. Expression profile of inflammatory cytokines in aqueous from glaucomatous eyes. Mol. Vis. 18, 431-438 (2012).

47. Engel, L. A., Muether, P. S., Fauser, S. \& Hueber, A. The effect of previous surgery and topical eye drops for primary open-angle glaucoma on cytokine expression in aqueous humor. Graefes. Arch Clin. Exp. Ophthalmol. 252, 791-799 (2014).

48. Freedman, J. \& Iserovich, P. Pro-inflammatory cytokines in glaucomatous aqueous and encysted Molteno implant blebs and their relationship to pressure. Invest. Ophthalmol. Vis. Sci. 54, 4851-4855 (2013).

49. Inoue-Mochita, M. et al. Interleukin-6-mediated trans-signaling inhibits transforming growth factor- $\beta$ signaling in trabecular meshwork cells. J. Biol. Chem. 293, 10975-10984 (2018).

50. Khalef, N. et al. Levels of cytokines in the aqueous humor of eyes with primary open angle glaucoma, pseudoexfoliation glaucoma and cataract. Electron. Phys. 9, 3833-3837 (2017).

51. Kuchtey, J., Rezaei, K. A., Jaru-Ampornpan, P., Sternberg, P. \& Kuchtey, R. W. Multiplex cytokine analysis reveals elevated concentration of interleukin-8 in glaucomatous aqueous humor. Invest. Ophthalmol. Vis. Sci. 51, 6441-6447 (2010).

52. Niu, J. Relation of serum and aqueous humor TNF- $\alpha$ and IL-6 with the process of neovascular glaucoma. Int. Eye Sci. 18, 1684-1686 (2018).

53. Ohira, S., Inoue, T., Iwao, K., Takahashi, E. \& Tanihara, H. Factors influencing aqueous proinflammatory cytokines and growth factors in uveitic glaucoma. PLoS ONE 11, e0147080 (2016).

54. Sorkhabi, R., Ghorbanihaghjo, A., Javadzadeh, A., Motlagh, B. F. \& Ahari, S. S. Aqueous humor hepcidin prohormone levels in patients with primary open angle glaucoma. Mol. Vis. 16, 1832-1836 (2010).

55. Takai, Y., Tanito, M. \& Ohira, A. Multiplex cytokine analysis of aqueous humor in eyes with primary open-angle glaucoma, exfoliation glaucoma, and cataract. Invest. Ophthalmol. Vis. Sci. 53, 241-247 (2012).

56. Ten Berge, J. C. et al. Intraocular cytokine profile and autoimmune reactions in retinitis pigmentosa, age-related macular degeneration, glaucoma and cataract. Acta Ophthalmol. 97, 185-192 (2019).

57. Zenkel, M. et al. Proinflammatory cytokines are involved in the initiation of the abnormal matrix process in pseudoexfoliation syndrome/glaucoma. Am. J. Pathol. 176, 2868-2879 (2010).

58. Du, S. et al. Multiplex cytokine levels of aqueous humor in acute primary angle-closure patients: Fellow eye comparison. BMC Ophthalmol. 16, 6 (2016).

59. Duvesh, R. et al. Multiplex cytokine analysis of aqueous humor from the patients with chronic primary angle closure glaucoma. Curr. Eye Res. 42, 1608-1613 (2017).

60. Liu, Y.-M. et al. Aqueous proinflammatory cytokines in acute primary angle-closure eyes. Int. J. Ophthalmol. 10, $733-737$ (2017).

61. Wang, Y. et al. Inflammatory cytokine profiles in eyes with primary angle-closure glaucoma. Biosci. Rep. 38, BSR20181411 (2018).

62. Kovacs, K. et al. Angiogenic and inflammatory vitreous biomarkers associated with increasing levels of retinal ischemia. Invest. Ophthalmol. Vis. Sci. 56, 6523-6530 (2015).

63. Li, J. et al. Aqueous cytokine changes associated with posner-schlossman syndrome with and without human cytomegalovirus. PLoS One 7, e44453 (2012).

64. Liu, Z., Fu, G. \& Liu, A. The relationship between inflammatory mediator expression in the aqueous humor and secondary glaucoma incidence after silicone oil tamponade. Exp. Ther. Med. 14, 5833-5836 (2017).

65. Rusnak, S. et al. The measurement of intraocular biomarkers in various stages of proliferative diabetic retinopathy using multiplex xMAP technology. J. Ophthalmol. 2015, 424783 (2015).

66. Vulovic, T. S. S., Pavlovic, S. M. \& Zdravkovic, N. S. Proinflammatory cytokines induce XFG development. Ocul. Immunol. Inflamm. 24, 671-677 (2016).

67. Garweg, J. G., Zandi, S., Pfister, I. B., Skowronska, M. \& Gerhardt, C. Comparison of cytokine profiles in the aqueous humor of eyes with pseudoexfoliation syndrome and glaucoma. PLoS ONE 12, e0182571 (2017).

68. Aketa, N. et al. Elevated aqueous cytokine levels in eyes with ocular surface diseases. Am. J. Ophthalmol. 184, 42-51 (2017).

69. Zhang, Y. et al. Expression of cytokines in aqueous humor from fungal keratitis patients. BMC Ophthalmol. 18, 105 (2018).

70. Ang, M. et al. Aqueous cytokine and chemokine analysis in uveitis associated with tuberculosis. Mol. Vis. 18, 565-573 (2012).

71. Aketa, N. et al. Iris damage is associated with elevated cytokine levels in aqueous humor. Invest. Ophthalmol. Vis. Sci. 58, BIO42BIO51 (2017).

72. Bae, J. H. \& Lee, S. C. Effect of intravitreal methotrexate and aqueous humor cytokine levels in refractory retinal vasculitis in Behcet disease. Retina (Philadelphia, Pa.) 32, 1395-1402 (2012).

73. Banerjee, S. et al. Multiplex bead analysis of vitreous humor of patients with vitreoretinal disorders. Invest. Ophthalmol. Vis. Sci. 48, 2203-2207 (2007).

74. Chen, W. et al. Discrepant expression of cytokines in inflammation- and age-related cataract patients. PLoS One 9, e109647 (2014).

75. Curnow, S. J. et al. Multiplex bead immunoassay analysis of aqueous humor reveals distinct cytokine profiles in uveitis. Invest. Ophthalmol. Vis. Sci. 46, 4251-4259 (2005).

76. Garfella, M. L. H., Fort, P. P., Ivorra, J. A. R. \& Taulet, E. C. Aqueous humor levels of different interleukins 1- $\beta, 2,6$ and 10, tumor necrosis factor- $\alpha$ and vascular endothelial growth factor in uveitis treated with adalimumab. J. Ophthalmic. Vis. Res. 10, 49-54 (2015).

77. Murray, P. I., Hoekzema, R., van Haren, M. A., de Hon, F. D. \& Kijlstra, A. Aqueous humor interleukin-6 levels in uveitis. Invest. Ophthalmol. Vis. Sci. 31, 917-920 (1990).

78. Murugeswari, P. et al. Proinflammatory cytokines and angiogenic and anti-angiogenic factors in vitreous of patients with proliferative diabetic retinopathy and eales' disease. Retina (Philadelphia, Pa.) 28, 817-824 (2008).

79. Murugeswari, P. et al. angiogenic potential of vitreous from proliferative diabetic retinopathy and Eales' disease patients. PLoS ONE 9, e107551 (2014).

80. Nagata, K. et al. Simultaneous analysis of multiple cytokines in the vitreous of patients with sarcoid uveitis. Invest. Ophthalmol. Vis. Sci. 53, 3827-3833 (2012).

81. Perez, V. L. et al. Elevated levels of interleukin 6 in the vitreous fluid of patients with pars planitis and posterior uveitis: the Massachusetts eye \& ear experience and review of previous studies. Ocul. Immunol. Inflamm. 12, 193-201 (2004). 
82. Petrinović-Doresić, J., Mazuran, R., Henc-Petrinović, L., Kuzmanović, B. \& Jovicić, A. Interleukin 6 and its soluble receptor are elevated in aqueous humor of patients with uveitis. Ocul. Immunol. Inflamm. 7, 75-84 (1999).

83. Sauer, A. et al. Intraocular cytokine levels in post-cataract endophthalmitis and their association with visual outcome. Ocul. Immunol. Inflamm. 26, 964-970 (2018).

84. Sijssens, K. M. et al. Cytokines, chemokines and soluble adhesion molecules in aqueous humor of children with uveitis. Exp. Eye Res. 85, 443-449 (2007).

85. van Kooij, B., Rothova, A., Rijkers, G. T. \& de Groot-Mijnes, J. D. F. Distinct cytokine and chemokine profiles in the aqueous of patients with uveitis and cystoid macular edema. Am. J. Ophthalmol. 142, 192-194 (2006).

86. Wakefield, D., McCluskey, P., Roche, N. \& Rossio, J. L. Aqueous humor cytokine profile in patients with chronic uveitis. Ocul. Immunol. Inflamm. 3, 203-208 (1995).

87. Boss, J. D. et al. Assessment of neurotrophins and inflammatory mediators in vitreous of patients with diabetic retinopathy. Invest. Ophthalmol. Vis. Sci. 58, 5594-5603 (2017).

88. Chen, H., Zhang, X., Liao, N. \& Wen, F. Assessment of biomarkers using multiplex assays in aqueous humor of patients with diabetic retinopathy. BMC Ophthalmol. 17, 176 (2017).

89. Chernykh, V. V., Varvarinsky, E. V., Smirnov, E. V., Chernykh, D. V. \& Trunov, A. N. Proliferative and inflammatory factors in the vitreous of patients with proliferative diabetic retinopathy. Indian J. Ophthalmol. 63, 33-36 (2015).

90. Cheung, C. M. G., Vania, M., Ang, M., Chee, S. P. \& Li, J. Comparison of aqueous humor cytokine and chemokine levels in diabetic patients with and without retinopathy. Mol. Vis. 18, 830-837 (2012).

91. Dong, N., Xu, B., Wang, B. \& Chu, L. Study of 27 aqueous humor cytokines in patients with type 2 diabetes with or without retinopathy. Mol. Vis. 19, 1734-1746 (2013).

92. Feng, S. et al. Levels of inflammatory cytokines IL-1 $\beta$, IL-6, IL-8, IL-17A, and TNF- $\alpha$ in aqueous humour of patients with diabetic retinopathy. J. Diabetes Res. 2018, 8546423 (2018).

93. Funatsu, H., Yamashita, H., Shimizu, E., Kojima, R. \& Hori, S. Relationship between vascular endothelial growth factor and interleukin-6 in diabetic retinopathy. Retina (Philadelphia, Pa.) 21, 469-477 (2001).

94. Gustavsson, C., Agardh, C.-D. \& Agardh, E. Profile of intraocular tumour necrosis factor- $\alpha$ and interleukin- 6 in diabetic subjects with different degrees of diabetic retinopathy. Acta Ophthalmol. 91, 445-452 (2013).

95. Oh, I. K., Kim, S.-W., Oh, J., Lee, T. S. \& Huh, K. Inflammatory and angiogenic factors in the aqueous humor and the relationship to diabetic retinopathy. Curr. Eye Res. 35, 1116-1127 (2010).

96. Sin, B. H., Kim, J. Y., Park, J. Y. \& Park, S. P. Analysis of intraocular cytokines according to progression of diabetic retinopathy and macular edema in diabetic patients. J. Korean Ophthalmol. Soc. 54, 618 (2013).

97. Suzuki, Y., Nakazawa, M., Suzuki, K., Yamazaki, H. \& Miyagawa, Y. Expression profiles of cytokines and chemokines in vitreous fluid in diabetic retinopathy and central retinal vein occlusion. Jpn. J. Ophthalmol. 55, 256-263 (2011).

98. Yuuki, T. et al. Inflammatory cytokines in vitreous fluid and serum of patients with diabetic vitreoretinopathy. J. Diabetes Compl. 15, 257-259 (2001).

99. el Asrar, A. M. A., Maimone, D., Morse, P. H., Gregory, S. \& Reder, A. T. Cytokines in the vitreous of patients with proliferative diabetic retinopathy. Am. J. Ophthalmol. 114, 731-736 (1992).

100. Adamiec-Mroczek, J. \& Oficjalska-Młyńczak, J. Assessment of selected adhesion molecule and proinflammatory cytokine levels in the vitreous body of patients with type 2 diabetes-role of the inflammatory-immune process in the pathogenesis of proliferative diabetic retinopathy. Graefes Arch. Clin. Exp. Ophthalmol. 246, 1665-1670 (2008).

101. Bromberg-White, J. L. et al. Identification of VEGF-independent cytokines in proliferative diabetic retinopathy vitreous. Invest. Ophthalmol. Vis. Sci. 54, 6472-6480 (2013).

102. Canataroglu, H. et al. Interleukin (IL)-6, interleukin (IL)-8 levels and cellular composition of the vitreous humor in proliferative diabetic retinopathy, proliferative vitreoretinopathy, and traumatic proliferative vitreoretinopathy. Ocul. Immunol. Inflamm. 13, 375-381 (2005).

103. Kauffmann, D. J. et al. Cytokines in vitreous humor: Interleukin-6 is elevated in proliferative vitreoretinopathy. Invest. Ophthalmol. Vis. Sci. 35, 900-906 (1994).

104. Koskela, U. E., Kuusisto, S. M., Nissinen, A. E., Savolainen, M. J. \& Liinamaa, M. J. High vitreous concentration of IL-6 and IL-8, but not of adhesion molecules in relation to plasma concentrations in proliferative diabetic retinopathy. Ophthalm. Res. 49, 108-114 (2013).

105. Loukovaara, S. et al. NLRP3 inflammasome activation is associated with proliferative diabetic retinopathy. Acta Ophthalmol. 95, 803-808 (2017).

106. Mocan, M. C., Kadayifcilar, S. \& Eldem, B. Elevated intravitreal interleukin-6 levels in patients with proliferative diabetic retinopathy. Can. J. Ophthalmol. 41, 747-752 (2006).

107. Nakamura, N. et al. Increased concentration of pentosidine, an advanced glycation end product, and interleukin-6 in the vitreous of patients with proliferative diabetic retinopathy. Diabetes Res. Clin. Pract. 61, 93-101 (2003).

108. Schoenberger, S. D. et al. Increased prostaglandin E2 (PGE2) levels in proliferative diabetic retinopathy, and correlation with VEGF and inflammatory cytokines. Invest. Ophthalmol. Vis. Sci. 53, 5906-5911 (2012).

109. Shimura, M. et al. Panretinal photocoagulation induces pro-inflammatory cytokines and macular thickening in high-risk proliferative diabetic retinopathy. Graefes Arch. Clin. Exp. Ophthalmol. 247, 1617-1624 (2009).

110. Song, Y. J., Jung, J. H. \& Kim, D. G. Analysis of aqueous humor cytokines in diabetic retinopathy. J. Korean Ophthalmol. Soc. 55, 1821 (2014).

111. Srividya, G. et al. A novel and less invasive technique to assess cytokine profile of vitreous in patients of diabetic macular oedema. Eye (Lond.) 32, 820-829 (2018).

112. Takahashi, S., Adachi, K., Suzuki, Y., Maeno, A. \& Nakazawa, M. Profiles of inflammatory cytokines in the vitreous fluid from patients with rhegmatogenous retinal detachment and their correlations with clinical features. Biomed. Res. Int. 2016, 4256183 (2016).

113. Tsai, T. et al. Anti-inflammatory cytokine and angiogenic factors levels in vitreous samples of diabetic retinopathy patients. PLoS ONE 13, e0194603 (2018).

114. Wu, H., Hwang, D.-K., Song, X. \& Tao, Y. Association between aqueous cytokines and diabetic retinopathy stage. J. Ophthalmol. 2017, 9402198 (2017).

115. Xu, Y. et al. Increased $\mathrm{sCD} 200$ levels in vitreous of patients with proliferative diabetic retinopathy and its correlation with VEGF and proinflammatory cytokines. Invest. Ophthalmol. Vis. Sci. 56, 6565-6572 (2015).

116. Yoshida, S. et al. Increased vitreous concentrations of MCP-1 and IL-6 after vitrectomy in patients with proliferative diabetic retinopathy: Possible association with postoperative macular oedema. Br. J. Ophthalmol. 99, 960-966 (2015).

117. Yoshimura, T. et al. Comprehensive analysis of inflammatory immune mediators in vitreoretinal diseases. PLoS One 4, e8158 (2009).

118. Zeng, Y. et al. Comprehensive analysis of vitreous humor chemokines in type 2 diabetic patients with and without diabetic retinopathy. Acta Diabetol. 56, 797-805 (2019).

119. Zhou, J., Wang, S. \& Xia, X. Role of intravitreal inflammatory cytokines and angiogenic factors in proliferative diabetic retinopathy. Curr. Eye Res. 37, 416-420 (2012). 
120. Mastropasqua, R. et al. Relationship between aqueous humor cytokine level changes and retinal vascular changes after intravitreal aflibercept for diabetic macular edema. Sci. Rep. 8, 16548 (2018).

121. Bandyopadhyay, S., Bandyopadhyay, S. K., Saha, M. \& Sinha, A. Study of aqueous cytokines in patients with different patterns of diabetic macular edema based on optical coherence tomography. Int. Ophthalmol. 38, 241-249 (2018).

122. Bayomy, N. R. \& Elgouhary, S. M. Association between aqueous levels of IL-6, TNF- $\alpha$ and VEGF with diabetic macular edema. Arab. J. Lab. Med. 43, 907-914 (2018).

123. Chen, H., Zhang, X., Liao, N. \& Wen, F. Increased levels of IL-6, sIL-6R, and sgp130 in the aqueous humor and serum of patients with diabetic retinopathy. Mol. Vis. 22, 1005-1014 (2016).

124. Dong, N., Xu, B., Wang, B., Chu, L. \& Tang, X. Aqueous cytokines as predictors of macular edema in patients with diabetes following uncomplicated phacoemulsification cataract surgery. Biomed. Res. Int. 2015, 126984 (2015).

125. Dong, N., Xu, B., Chu, L. \& Tang, X. Study of 27 aqueous humor cytokines in type 2 diabetic patients with or without macular edema. PLoS ONE 10, e0125329 (2015).

126. Funatsu, H. et al. Increased levels of vascular endothelial growth factor and interleukin-6 in the aqueous humor of diabetics with macular edema. Am. J. Ophthalmol. 133, 70-77 (2002).

127. Funatsu, H. et al. Vitreous levels of interleukin-6 and vascular endothelial growth factor are related to diabetic macular edema. Ophthalmology 110, 1690-1696 (2003).

128. Funatsu, H., Noma, H., Mimura, T., Eguchi, S. \& Hori, S. Association of vitreous inflammatory factors with diabetic macular edema. Ophthalmology 116, 73-79 (2009).

129. Funk, M. et al. Angiogenic and inflammatory markers in the intraocular fluid of eyes with diabetic macular edema and influence of therapy with bevacizumab. Retina (Philadelphia, Pa.) 30, 1412-1419 (2010).

130. Jonas, J. B., Jonas, R. A., Neumaier, M. \& Findeisen, P. Cytokine concentration in aqueous humor of eyes with diabetic macular edema. Retina (Philadelphia, Pa.) 32, 2150-2157 (2012).

131. Kim, J. Y., Jeong, Y. J. \& Park, S. P. Different concentrations of aqueous cytokines according to diabetic macular edema patterns as determined optical coherence tomography. J. Clin. Exp. Ophthalmol. 5, 380 (2014).

132. Kim, M., Kim, Y. \& Lee, S.-J. Comparison of aqueous concentrations of angiogenic and inflammatory cytokines based on optical coherence tomography patterns of diabetic macular edema. Indian J. Ophthalmol. 63, 312-317 (2015).

133. Lee, W. J., Kang, M. H., Seong, M. \& Cho, H. Y. Comparison of aqueous concentrations of angiogenic and inflammatory cytokines in diabetic macular oedema and macular oedema due to branch retinal vein occlusion. Br. J. Ophthalmol. 96, 1426-1430 (2012).

134. Noma, H. et al. Aqueous humor levels of soluble vascular endothelial growth factor receptor and inflammatory factors in diabetic macular edema. Ophthalmologica 238, 81-88 (2017).

135. Sohn, H. J. et al. Changes in aqueous concentrations of various cytokines after intravitreal triamcinolone versus bevacizumab for diabetic macular edema. Am. J. Ophthalmol. 152, 686-694 (2011).

136. Sonoda, S. et al. Correlation between reflectivity of subretinal fluid in OCT images and concentration of intravitreal VEGF in eyes with diabetic macular edema. Invest. Ophthalmol. Vis. Sci. 54, 5367-5374 (2013).

137. Wen, J., Jiang, Y., Zheng, X. \& Zhou, Y. Six-month changes in cytokine levels after intravitreal bevacizumab injection for diabetic macular oedema and macular oedema due to central retinal vein occlusion. Br. J. Ophthalmol. 99, 1334-1340 (2015).

138. Yu, S.-Y., Nam, D. H. \& Lee, D. Y. Changes in aqueous concentrations of various cytokines after intravitreal bevacizumab and subtenon triamcinolone injection for diabetic macular edema. Graefes Arch. Clin. Exp. Ophthalmol. 256, 39-47 (2018).

139. Chu, L., Wang, B., Xu, B. \& Dong, N. Aqueous cytokines as predictors of macular edema in non-diabetic patients following uncomplicated phacoemulsification cataract surgery. Mol. Vis. 19, 2418-2425 (2013).

140. Noma, H., Funatsu, H. \& Mimura, T. Vascular endothelial growth factor and interleukin-6 are correlated with serous retinal detachment in central retinal vein occlusion. Curr. Eye Res. 37, 62-67 (2012).

141. Roh, M. I., Kim, H. S., Song, J. H., Lim, J. B. \& Kwon, O. W. Effect of intravitreal bevacizumab injection on aqueous humor cytokine levels in clinically significant macular edema. Ophthalmology 116, 80-86 (2009).

142. Feng, J., Zhao, T., Zhang, Y., Ma, Y. \& Jiang, Y. Differences in aqueous concentrations of cytokines in macular edema secondary to branch and central retinal vein occlusion. PLoS ONE 8, e68149 (2013).

143. Jung, S. H., Kim, K.-A., Sohn, S. W. \& Yang, S. J. Association of aqueous humor cytokines with the development of retinal ischemia and recurrent macular edema in retinal vein occlusion. Invest. Ophthalmol. Vis. Sci. 55, 2290-2296 (2014).

144. Ehlken, C. et al. Increased expression of angiogenic and inflammatory proteins in the vitreous of patients with ischemic central retinal vein occlusion. PLoS ONE 10, e0126859 (2015).

145. Funk, M. et al. Intraocular concentrations of growth factors and cytokines in retinal vein occlusion and the effect of therapy with bevacizumab. Invest. Ophthalmol. Vis. Sci. 50, 1025-1032 (2009).

146. Koss, M. J. et al. Comparison of cytokine levels from undiluted vitreous of untreated patients with retinal vein occlusion. Acta Ophthalmol. 90, e98-e103 (2012).

147. Koss, M. et al. Correlation from undiluted vitreous cytokines of untreated central retinal vein occlusion with spectral domain optical coherence tomography. Open Ophthalmol. J. 7, 11-17 (2013).

148. Noma, H. et al. Increase of vascular endothelial growth factor and interleukin-6 in the aqueous humour of patients with macular oedema and central retinal vein occlusion. Acta Ophthalmol. 88, 646-651 (2010).

149. Noma, H., Mimura, T., Tatsugawa, M. \& Shimada, K. Aqueous flare and inflammatory factors in macular edema with central retinal vein occlusion: A case series. BMC Ophthalmol. 13, 78 (2013).

150. Noma, H., Mimura, T., Yasuda, K. \& Shimura, M. Role of soluble vascular endothelial growth factor receptor signaling and other factors or cytokines in central retinal vein occlusion with macular edema. Invest. Ophthalmol. Vis. Sci. 56, 1122-1128 (2015).

151. Rezar-Dreindl, S. et al. Effect of intravitreal dexamethasone implant on intra-ocular cytokines and chemokines in eyes with retinal vein occlusion. Acta Ophthalmol. 95, e119-e127 (2017).

152. Shchuko, A. G. et al. Intraocular cytokines in retinal vein occlusion and its relation to the efficiency of anti-vascular endothelial growth factor therapy. Indian J. Ophthalmol. 63, 905-911 (2015).

153. Kaneda, S. et al. Multivariate analyses of inflammatory cytokines in eyes with branch retinal vein occlusion: Relationships to bevacizumab treatment. Invest. Ophthalmol. Vis. Sci. 52, 2982-2988 (2011).

154. Lim, J. W. Intravitreal bevacizumab and cytokine levels in major and macular branch retinal vein occlusion. Ophthalmologica 225, 150-154 (2011)

155. Noma, H. et al. Pathogenesis of macular edema with branch retinal vein occlusion and intraocular levels of vascular endothelial growth factor and interleukin-6. Am. J. Ophthalmol. 140, 256-261 (2005).

156. Noma, H. et al. Intravitreal levels of vascular endothelial growth factor and interleukin-6 are correlated with macular edema in branch retinal vein occlusion. Graefes Arch. Clin. Exp. Ophthalmol. 244, 309-315 (2006).

157. Noma, H., Mimura, T. \& Eguchi, S. Association of inflammatory factors with macular edema in branch retinal vein occlusion. JAMA Ophthalmol. 131, 160-165 (2013).

158. Noma, H., Mimura, T. \& Shimada, K. Role of inflammation in previously untreated macular edema with branch retinal vein occlusion. BMC Ophthalmol. 14, 67 (2014).

159. Noma, H., Mimura, T., Yasuda, K. \& Shimura, M. Role of soluble vascular endothelial growth factor receptors-1 and -2 , their ligands, and other factors in branch retinal vein occlusion with macular edema. Invest. Ophthalmol. Vis. Sci. 55, 3878-3885 (2014). 
160. Noma, H. et al. Intravitreal ranibizumab and aqueous humor factors/cytokines in major and macular branch retinal vein occlusion. Ophthalmologica 235, 203-207 (2016).

161. Park, S. P. \& Ahn, J. K. Changes of aqueous vascular endothelial growth factor and interleukin- 6 after intravitreal triamcinolone for branch retinal vein occlusion. Clin. Exp. Ophthalmol. 36, 831-835 (2008).

162. Pfister, M. et al. Correlation of inflammatory and proangiogenic cytokines from undiluted vitreous samples with spectral domain OCT scans, in untreated branch retinal vein occlusion. Clin. Ophthalmol. 7, 1061-1067 (2013).

163. Shimura, M. et al. Visual prognosis and vitreous cytokine levels after arteriovenous sheathotomy in branch retinal vein occlusion associated with macular oedema. Acta Ophthalmol. 86, 377-384 (2008).

164. Sohn, H. J., Han, D. H., Lee, D. Y. \& Nam, D. H. Changes in aqueous cytokines after intravitreal triamcinolone versus bevacizumab for macular oedema in branch retinal vein occlusion. Acta Ophthalmol. 92, e217-224 (2014).

165. Kramer, M. et al. Inflammatory reaction in acute retinal artery occlusion: Cytokine levels in aqueous humor and serum. Ocul. Immunol. Inflamm. 13, 305-310 (2005).

166. Agawa, T. et al. Profile of intraocular immune mediators in patients with age-related macular degeneration and the effect of intravitreal bevacizumab injection. Retina (Philadelphia, Pa.) 34, 1811-1818 (2014).

167. Feng, J., Chen, L., Yuan, M., Pan, C. \& Jiang, Y. Aqueous humor levels of cytokines in polypoidal choroidal vasculopathy and age-related macular degeneration. Int. J. Clin. Exp. Med. 11, 7270-7278 (2018).

168. Chalam, K. V., Grover, S., Sambhav, K., Balaiya, S. \& Murthy, R. K. Aqueous interleukin-6 levels are superior to vascular endothelial growth factor in predicting therapeutic response to bevacizumab in age-related macular degeneration. J. Ophthalmol. 2014, $502174(2014)$

169. Mimura, T. et al. Aqueous humor levels of cytokines in patients with age-related macular degeneration. Ophthalmologica 241, 81-89 (2019).

170. Motohashi, R. et al. Dynamics of inflammatory factors in aqueous humor during ranibizumab or aflibercept treatment for agerelated macular degeneration. Ophthalm. Res. 58, 209-216 (2017).

171. Kramer, M. et al. Monocyte chemoattractant protein-1 in the aqueous humour of patients with age-related macular degeneration. Clin. Exp. Ophthalmol. 40, 617-625 (2012).

172. Spindler, J., Zandi, S., Pfister, I. B., Gerhardt, C. \& Garweg, J. G. Cytokine profiles in the aqueous humor and serum of patients with dry and treated wet age-related macular degeneration. PLoS ONE 13, e0203337 (2018).

173. Fauser, S., Viebahn, U. \& Muether, P. S. Intraocular and systemic inflammation-related cytokines during one year of ranibizumab treatment for neovascular age-related macular degeneration. Acta Ophthalmol. 93, 734-738 (2015).

174. Jonas, J. B., Tao, Y., Neumaier, M. \& Findeisen, P. Cytokine concentration in aqueous humour of eyes with exudative age-related macular degeneration. Acta Ophthalmol. 90, e381-388 (2012).

175. Miao, H., Tao, Y. \& Li, X. Inflammatory cytokines in aqueous humor of patients with choroidal neovascularization. Mol. Vis. 18, 574-580 (2012).

176. Rezar-Dreindl, S. et al. The intraocular cytokine profile and therapeutic response in persistent neovascular age-related macular degeneration. Invest. Ophthalmol. Vis. Sci. 57, 4144-4150 (2016).

177. Sakurada, Y. et al. Aqueous humor cytokine levels in patients with polypoidal choroidal vasculopathy and neovascular age-related macular degeneration. Ophthalm. Res. 53, 2-7 (2015).

178. Sato, T., Takeuchi, M., Karasawa, Y., Enoki, T. \& Ito, M. Intraocular inflammatory cytokines in patients with neovascular agerelated macular degeneration before and after initiation of intravitreal injection of anti-VEGF inhibitor. Sci. Rep. 8, 1098 (2018).

179. Terao, N. et al. Distinct aqueous humour cytokine profiles of patients with pachychoroid neovasculopathy and neovascular age-related macular degeneration. Sci. Rep. 8, 10520 (2018).

180. Fan, X., Gao, N., Li, J., Lei, J. \& Kang, Q. Effects of VEGF levels on anti-VEGF therapy for patients with idiopathic choroidal neovascularization. Mol. Cell Biochem. 441, 173-179 (2018).

181. Roh, M. I. et al. Concentration of cytokines in the aqueous humor of patients with naive, recurrent and regressed CNV associated with amd after bevacizumab treatment. Retina (Philadelphia, Pa.) 29, 523-529 (2009).

182. Roh, M. I., Lim, S. J., Ahn, J. M., Lim, J. B. \& Kwon, O. W. Concentration of cytokines in age-related macular degeneration after consecutive intravitreal bevacizumab injection. Graefes Arch. Clin. Exp. Ophthalmol. 248, 635-640 (2010).

183. Jung, S. H., Kim, K.-A., Sohn, S. W. \& Yang, S. J. Cytokine levels of the aqueous humour in central serous chorioretinopathy. Clin. Exp. Optom. 97, 264-269 (2014).

184. Shin, M. C. \& Lim, J. W. Concentration of cytokines in the aqueous humor of patients with central serous chorioretinopathy. Retina (Philadelphia, Pa.) 31, 1937-1943 (2011).

185. Hu, J. et al. The features of inflammation factors concentrations in aqueous humor of polypoidal choroidal vasculopathy. PLoS ONE 11, e0147346 (2016).

186. Asensio-Sánchez, V. M., Collazos, J. M. \& Cantón, M. Interleukin-6 concentrations in the vitreous body of patients with retinal detachment. Arch. Soc. Esp. Oftalmol. 90, 527-530 (2015).

187. Garweg, J. G. et al. Cytokine profiles of phakic and pseudophakic eyes with primary retinal detachment. Acta Ophthalmol. 97, e580-e588 (2019).

188. Kunikata, H. et al. Intraocular concentrations of cytokines and chemokines in rhegmatogenous retinal detachment and the effect of intravitreal triamcinolone acetonide. Am. J. Ophthalmol. 155, 1028-1037.e1 (2013).

189. Yamamoto, H., Hayashi, H., Uchida, H., Kato, H. \& Oshima, K. Increased soluble interleukin-6 receptor in vitreous fluid of proliferative vitreoretinopathy. Curr. Eye Res. 26, 9-14 (2003).

190. Sato, T., Kusaka, S., Shimojo, H. \& Fujikado, T. Simultaneous analyses of vitreous levels of 27 cytokines in eyes with retinopathy of prematurity. Ophthalmology 116, 2165-2169 (2009).

191. Feng, J., Zheng, X., Li, B. \& Jiang, Y. Differences in aqueous concentrations of cytokines in paediatric and adult patients with Coats' disease. Acta Ophthalmol. 95, 608-612 (2017).

192. Yoshida, N. et al. Clinical evidence of sustained chronic inflammatory reaction in retinitis pigmentosa. Ophthalmology 120, $100-105$ (2013).

193. Zandi, S. et al. Vitreal cytokine profile differences between eyes with epiretinal membranes or macular holes. Invest. Ophthalmol. Vis. Sci. 57, 6320-6326 (2016).

194. Jakobsson, G., Sundelin, K., Zetterberg, H. \& Zetterberg, M. Increased levels of inflammatory immune mediators in vitreous from pseudophakic eyes. Invest. Ophthalmol. Vis. Sci. 56, 3407-3414 (2015).

195. Kuiper, J. J. W., Mutis, T., de Jager, W., de Groot-Mijnes, J. D. F. \& Rothova, A. Intraocular interleukin-17 and proinflammatory cytokines in HLA-A29-associated birdshot chorioretinopathy. Am. J. Ophthalmol. 152, 177-182.e1 (2011).

196. Nagarkatti-Gude, N., Bronkhorst, I. H. G., van Duinen, S. G., Luyten, G. P. M. \& Jager, M. J. Cytokines and chemokines in the vitreous fluid of eyes with uveal melanoma. Invest. Ophthalmol. Vis. Sci. 53, 6748-6755 (2012).

197. Sauer, A., Bourcier, T., Gaucher, D., Candolfi, E. \& Speeg-Schatz, C. Intraocular cytokines imbalance in congenital cataract and its impact on posterior capsule opacification. Graefes Arch. Clin. Exp. Ophthalmol. 254, 1013-1018 (2016).

198. Suzuki, N. et al. Cytokine levels in the aqueous humor are associated with corneal thickness in eyes with bullous keratopathy. Am. J. Ophthalmol. 198, 174-180 (2019).

199. Xiangiia, Z. et al. Proinflammatory status in the aqueous humor of high myopic cataract eyes. Exp. Eye Res. 142, 13-18 (2015). 
200. Acera, A., Rocha, G., Vecino, E., Lema, I. \& Durán, J. A. Inflammatory markers in the tears of patients with ocular surface disease. Ophthalm. Res. 40, 315-321 (2008).

201. Benitez-Del-Castillo, J., Cantu-Dibildox, J., Sanz-González, S. M., Zanón-Moreno, V. \& Pinazo-Duran, M. D. Cytokine expression in tears of patients with glaucoma or dry eye disease: A prospective, observational cohort study. Eur. J. Ophthalmol. 29, 437-443 (2019).

202. Chao, C. et al. Potential role of ocular microbiome, host genotype, tear cytokines, and environmental factors in corneal infiltrative events in contact lens wearers. Invest. Ophthalmol. Vis. Sci. 59, 5752-5761 (2018).

203. Elgin, C. Y., İskeleli, G., Talaz, S. \& Akyol, S. Comparative analysis of tear film levels of inflammatory mediators in contact lens users. Curr. Eye Res. 41, 441-447 (2016).

204. Erdogan-Poyraz, C. et al. Elevated tear interleukin-6 and interleukin-8 levels in patients with conjunctivochalasis. Cornea 28, 189-193 (2009).

205. Fodor, M. et al. Enhanced release of IL-6 and IL-8 into tears in various anterior segment eye diseases. Ophthalm. Res. 38, 182-188 (2006).

206. González-Pérez, J. et al. Tear film inflammatory mediators during continuous wear of contact lenses and corneal refractive therapy. Br. J. Ophthalmol. 96, 1092-1098 (2012).

207. Jackson, D. C. et al. Tear interferon-gamma as a biomarker for evaporative dry eye disease. Invest. Ophthalmol. Vis. Sci. 57, $4824-4830$ (2016).

208. Jun, A. S. et al. Subnormal cytokine profile in the tear fluid of keratoconus patients. PLoS ONE 6, e16437 (2011).

209. Jung, J. W. et al. Meibomian gland dysfunction and tear cytokines after cataract surgery according to preoperative meibomian gland status. Clin. Exp. Ophthalmol. 44, 555-562 (2016).

210. Lam, H. et al. Tear cytokine profiles in dysfunctional tear syndrome. Am. J. Ophthalmol. 147, 198-e1 (2009).

211. Landsend, E. C. S. et al. The level of inflammatory tear cytokines is elevated in congenital aniridia and associated with meibomian gland dysfunction. Invest. Ophthalmol. Vis. Sci. 59, 2197-2204 (2018).

212. Lee, S. Y. et al. Analysis of tear cytokines and clinical correlations in Sjögren syndrome dry eye patients and non-Sjögren syndrome dry eye patients. Am. J. Ophthalmol. 156, 247-253.e1 (2013).

213. Lema, I. \& Durán, J. A. Inflammatory molecules in the tears of patients with keratoconus. Ophthalmology 112, 654-659 (2005).

214. Lema, I., Sobrino, T., Durán, J. A., Brea, D. \& Díez-Feijoo, E. Subclinical keratoconus and inflammatory molecules from tears. Br. J. Ophthalmol. 93, 820-824 (2009).

215. Leonardi, A., Borghesan, F., DePaoli, M., Plebani, M. \& Secchi, A. G. Procollagens and inflammatory cytokine concentrations in tarsal and limbal vernal keratoconjunctivitis. Exp. Eye Res. 67, 105-112 (1998).

216. Massingale, M. L. et al. Analysis of inflammatory cytokines in the tears of dry eye patients. Cornea 28, 1023-1027 (2009).

217. Matsumura, N. et al. Cytokine profiles of tear fluid from patients with pediatric lacrimal duct obstruction. Invest. Ophthalmol. Vis. Sci. 58, 252-256 (2017).

218. McDonnell, P. J. et al. Study design and baseline findings from the progression of ocular findings (PROOF) natural history study of dry eye. BMC Ophthalmol. 17, 265 (2017).

219. Mrugacz, M. et al. Pro-inflammatory cytokines associated with clinical severity of dry eye disease of patients with depression. Adv. Med. Sci. 62, 338-344 (2017).

220. Nivenius, E., Van der Ploeg, I., Gafvelin, G., Van Hage, M. \& Montan, P. G. Conjunctival provocation with airborne allergen in patients with atopic keratoconjunctivitis. Clin. Exp. Allergy 42, 58-65 (2012).

221. Oray, M. \& Toker, E. Tear cytokine levels in vernal keratoconjunctivitis: The effect of topical $0.05 \%$ cyclosporine a therapy. Cornea 32, 1149-1154 (2013)

222. Pflugfelder, S. C., Jones, D., Ji, Z., Afonso, A. \& Monroy, D. Altered cytokine balance in the tear fluid and conjunctiva of patients with Sjögren's syndrome keratoconjunctivitis sicca. Curr. Eye Res. 19, 201-211 (1999).

223. Saeki, Y., Kadonosono, K. \& Uchio, E. Clinical and allergological analysis of ocular manifestations of sick building syndrome. Clin. Ophthalmol. 11, 517-522 (2017).

224. Sakimoto, T., Ohnishi, T. \& Ishimori, A. Simultaneous study of matrix metalloproteinases, proinflammatory cytokines, and soluble cytokine receptors in the tears of noninfectious corneal ulcer patients. Graefes Arch. Clin. Exp. Ophthalmol. 252, 1451-1456 (2014).

225. Santacruz, C. et al. Expression of IL-8, IL-6 and IL-1 $\beta$ in tears as a main characteristic of the immune response in human microbial keratitis. Int. J. Mol. Sci. 16, 4850-4864 (2015).

226. Shetty, R. et al. Elevated expression of matrix metalloproteinase- 9 and inflammatory cytokines in keratoconus patients is inhibited by cyclosporine A. Invest. Ophthalmol. Vis. Sci. 56, 738-750 (2015).

227. Shetty, R., Deshmukh, R., Ghosh, A., Sethu, S. \& Jayadev, C. Altered tear inflammatory profile in Indian keratoconus patientsThe 2015 Col Rangachari Award paper. Indian J. Ophthalmol. 65, 1105-1108 (2017).

228. Sorkhabi, R., Ghorbanihaghjo, A., Taheri, N. \& Ahoor, M. H. Tear film inflammatory mediators in patients with keratoconus. Int. Ophthalmol. 35, 467-472 (2015).

229. Tai, E. L. M. et al. Tear cytokine levels in allergic rhinitis without ocular symptoms. Can. J. Ophthalmol. https://doi.org/10.1016/J. JCJO.2018.12.003 (2019).

230. Tishler, M. et al. Elevated tear interleukin-6 levels in patients with Sjögren syndrome. Ophthalmology 105, 2327-2329 (1998).

231. Ujhelyi, B. et al. Graves' orbitopathy results in profound changes in tear composition: A study of plasminogen activator inhibitor-1 and seven cytokines. Thyroid 22, 407-414 (2012).

232. Van Acker, S. I. et al. Pterygium pathology: A prospective case-control study on tear film cytokine levels. Mediators Inflamm. 2019, $9416262(2019)$.

233. Zhao, H., Li, Q., Ye, M. \& Yu, J. Tear luminex analysis in dry eye patients. Med. Sci. Monit. 24, 7595-7602 (2018).

234. Yao, Y. et al. Interleukin-6 and diabetic retinopathy: A systematic review and meta-analysis. Curr. Eye Res. 44, 564-574 (2019).

235. Akkaya, S. Spectrum of pachychoroid diseases. Int. Ophthalmol. 38, 2239-2246 (2018).

236. Rudofsky, G. Jr. et al. The $-174 \mathrm{G}>\mathrm{C}$ IL-6 gene promoter polymorphism and diabetic microvascular complications. Horm. Metab. Res. 41, 308-313 (2009).

237. Teixeira, A. A., Quinto, B. M. R., Dalboni, M. A., Rodrigues, C. J. O. \& Batista, M. C. Association of IL-6 polymorphism -174G/C and metabolic syndrome in hypertensive patients. Biomed. Res. Int. 2015, 927589 (2015).

238. Brull, D. J. et al. Interleukin-6 gene $-174 \mathrm{~g}>\mathrm{c}$ and $-572 \mathrm{~g}>\mathrm{c}$ promoter polymorphisms are strong predictors of plasma interleukin- 6 levels after coronary artery bypass surgery. Arterioscler. Thromb. Vasc. Biol. 21, 1458-1463 (2001).

239. Ravaglia, G. et al. Associations of the $-174 \mathrm{G} / \mathrm{C}$ interleukin- 6 gene promoter polymorphism with serum interleukin 6 and mortality in the elderly. Biogerontology 6, 415-423 (2005).

240. Möhlig, M. et al. Body mass index and C-174G interleukin-6 promoter polymorphism interact in predicting type 2 diabetes. J. Clin. Endocrinol. Metab. 89, 1885-1890 (2004).

241. Testa, R. et al. Interleukin-6-174 G > C polymorphism affects the association between IL-6 plasma levels and insulin resistance in type 2 diabetic patients. Diabetes Res. Clin. Pract. 71, 299-305 (2006).

242. Järgen, P., Dietrich, A., Herling, A. W., Hammes, H.-P. \& Wohlfart, P. The role of insulin resistance in experimental diabetic retinopathy-Genetic and molecular aspects. PLoS ONE 12, e0178658 (2017). 
243. Rojas, M. A. et al. Interleukin 6 has a critical role in diabetes-induced retinal vascular inflammation and permeability. Invest. Ophthalmol. Vis. Sci. 52, 1003-1003 (2011).

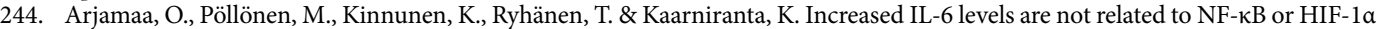
transcription factors activity in the vitreous of proliferative diabetic retinopathy. J. Diabetes Compl. 25, 393-397 (2011).

245. Rowe, C. W. et al. Insulin resistance correlates with maculopathy and severity of retinopathy in young adults with Type 1 Diabetes Mellitus. Diabetes Res. Clin. Pract. 131, 154-160 (2017).

246. Rho, C. R. et al. A strong association of rs 1800796 of IL6 and rs4845617 of IL6R in Korean patients with dry eye disease. Invest Ophthalmol. Vis. Sci. 53, 541-541 (2012).

247. Zhou, G. \& Liu, B. Single nucleotide polymorphisms of metabolic syndrome-related genes in primary open angle glaucoma. Int. J. Ophthalmol. 3, 36-42 (2010).

248. Edmunds, L.E., Loh, A.R., Fenerty, C., \& Papadopoulos, M. Secondary glaucoma: Glaucoma associated with acquired conditions. American Academy of Ophthalmology. https://www.aao.org/disease-review/secondary-glaucoma-glaucoma-associated -with-acquir (2015).

249. Xin, X., Gao, L., Wu, T. \& Sun, F. Roles of tumor necrosis factor alpha gene polymorphisms, tumor necrosis factor alpha level in aqueous humor, and the risks of open angle glaucoma: A meta-analysis. Mol. Vis. 19, 526-535 (2013).

250. Ulhaq, Z. S. Chemokine IL-8 level in aqueous humor of open-angle glaucoma: A meta-analysis. Arch. Soc. Esp. Oftalmol. 95, $114-119(2020)$.

251. Franco-Cardenas, V. et al. Assessment of ischemic index in retinal vascular diseases using ultra-wide-field fluorescein angiography: Single versus summarized image. Semin. Ophthalmol. 32, 353-357 (2017).

252. Yasuda, S. et al. Electroretinograms and level of aqueous vascular endothelial growth factor in eyes with hemicentral retinal vein occlusion or branch retinal vein occlusion. Jpn. J. Ophthalmol. 58, 232-236 (2014).

253. Rojas, M. et al. Role of IL-6 in angiotensin II-induced retinal vascular inflammation. Invest. Ophthalmol. Vis. Sci. 51, 1709-1718 (2010).

254. Sève, P. et al. Uveitis: Diagnostic work-up. A literature review and recommendations from an expert committee. Autoimmun. Rev. 16, 1254-1264 (2017).

255. Chen, W. et al. Cytokine expression profile in aqueous humor and sera of patients with acute anterior uveitis. Curr. Mol. Med. 15, 543-549 (2015).

256. Zelazowska-Rutkowska, B., Mrugacz, M. \& Cylwik, B. Comparison of the diagnostic power of serum IL-6, IL-8 and TNF- $\alpha$ for the idiopathic anterior uveitis in children. Clin. Lab. 63, 1889-1895 (2017).

257. Daruich, A. et al. Mechanisms of macular edema: Beyond the surface. Prog. Retin. Eye. Res. 63, 20-68 (2018).

258. Kent, D., Vinores, S. \& Campochiaro, P. Macular oedema: The role of soluble mediators. Br. J. Ophthalmol. 84, 542-545 (2000).

259. Rotsos, T. G. \& Moschos, M. M. Cystoid macular edema. Clin. Ophthalmol. 2, 919-930 (2008).

260. Mesquida, M. et al. Modelling macular edema: the effect of IL-6 and IL-6R blockade on human blood-retinal barrier integrity in vitro. Transl. Vis. Sci. Technol. 8, 32 (2019).

261. Muselier, A. et al. Efficacy of tocilizumab in two patients with anti-TNF-alpha refractory uveitis. Ocul. Immunol. Inflamm. 19, 382-383 (2011)

262. Adán, A. et al. Tocilizumab treatment for refractory uveitis-related cystoid macular edema. Graefes Arch. Clin. Exp. Ophthalmol. 251, 2627-2632 (2013).

263. Mesquida, M., Molins, B., Llorenç, V., de la Maza, M. S. \& Adán, A. Long-term effects of tocilizumab therapy for refractory uveitis-related macular edema. Ophthalmology 121, 2380-2386 (2014).

264. Papo, M. et al. Tocilizumab in severe and refractory non-infectious uveitis. Clin. Exp. Rheumatol. 32, S75-79 (2014).

265. Sepah, Y. J. et al. Primary (Month-6) outcomes of the STOP-uveitis study: Evaluating the safety, tolerability, and efficacy of tocilizumab in patients with noninfectious uveitis. Am.J. Ophthalmol. 183, 71-80 (2017).

266. Perez-Moreiras, J. V. et al. Efficacy of tocilizumab in patients with moderate-to-severe corticosteroid-resistant graves orbitopathy: A randomized clinical trial. Am. J. Ophthalmol. 195, 181-190 (2018).

267. Heissigerová, J. et al. Efficacy and safety of Sarilumab for the Treatment of Posterior Segment Noninfectious Uveitis (SARILNIU): The phase 2 SATURN Study. Ophthalmology 126, 428-437 (2019).

268. Wang, X. et al. Rapid monocyte infiltration following retinal detachment is dependent on non-canonical IL6 signaling through gp130. J. Neuroinflam. 14, 121 (2017).

269. Ricker, L. J. A. G. et al. Interleukin and growth factor levels in subretinal fluid in rhegmatogenous retinal detachment: A casecontrol study. PLoS One 6, e19141 (2011).

270. Zandi, S. et al. Biomarkers for PVR in rhegmatogenous retinal detachment. PLoS One 14, e0214674 (2019).

271. Ulhaq, Z. S. \& Soraya, G. V. Roles of IL-8 $-251 \mathrm{~A} / \mathrm{T}$ and $+781 \mathrm{C} / \mathrm{T}$ polymorphisms, IL-8 level, and the risk of age-related macular degeneration. Arch. Soc. Esp. Oftalmol. (2020).

272. Terao, N. et al. Association of upregulated angiogenic cytokines with choroidal abnormalities in chronic central serous chorioretinopathy. Invest. Ophthalmol. Vis. Sci. 59, 5924-5931 (2018).

273. Moher, D., Liberati, A., Tetzlaff, J., Altman, D. G. \& PRISMA Group. Preferred reporting items for systematic reviews and metaanalyses: The PRISMA statement. PLoS Med. 6, e1000097 (2009).

274. Hozo, S. P., Djulbegovic, B. \& Hozo, I. Estimating the mean and variance from the median, range, and the size of a sample. BMC Med. Res. Methodol. 5, 13 (2005).

275. Wan, X., Wang, W., Liu, J. \& Tong, T. Estimating the sample mean and standard deviation from the sample size, median, range and/or interquartile range. BMC Med. Res. Methodol. 14, 135 (2014).

276. Ulhaq, Z. S. \& Soraya, G. V. Aqueous humor interleukin-6 levels in primary open-angle glaucoma (POAG): A systematic review and meta-analysis. Arch. Soc. Esp. Oftalmol. 95, 315-321 (2020).

277. Soraya, G. V. \& Ulhaq, Z. S. Crucial laboratory parameters in COVID-19 diagnosis and prognosis: An updated meta-analysis. Med. Clin. (Barc.) 155, 143-151 (2020).

278. Ulhaq, Z. S. \& Garcia, C. P. Estrogen receptor beta (ESR2) gene polymorphism and susceptibility to dementia. Acta Neurol. Belg.. https://doi.org/10.1007/s13760-020-01360-z (2020).

279. Ulhaq, Z. S. Genetic polymorphisms associated with age-related macular degeneration. Int. J. Retina 3, 1 (2020).

280. Ulhaq, Z. S. \& Garcia, C. P. Inflammation-related gene polymorphisms associated with Parkinson's disease: An updated metaanalysis. Egypt. J. Med. Hum. Genet. 21, 14 (2020).

281. Ulhaq, Z. S. \& Soraya, G. V. Interleukin-6 as a potential biomarker of COVID-19 progression. Med. Mal. Infect. 50, 382-383 (2020).

282. Soraya, G. V. \& Ulhaq, Z. S. Interleukin-6 levels in children developing SARS-CoV-2 infection. Pediatr. Neonatol. 61, 253-254 (2020).

283. Ulhaq, Z. S., Soraya, G. V. \& Fauziah, F. A. Recurrent positive SARS-CoV-2 RNA tests in recovered and discharged patients. Rev. Clin. Esp.. https://doi.org/10.1016/j.rce.2020.06.012 (2020).

284. Ulhaq, Z. S. The association of estrogen-signaling pathways and susceptibility to open-angle glaucoma. Beni-Suef Univ. J. Basic Appl. Sci. 9, 7 (2020).

285. Ulhaq, Z. S. \& Soraya, G. V. The prevalence of ophthalmic manifestations in COVID-19 and the diagnostic value of ocular tissue/ fluid. Graefes Arch. Clin. Exp. Ophthalmol. 258, 1351-1352 (2020). 
286. Ulhaq, Z. S. Update on 'Associations of estrogen receptor alpha gene polymorphisms with type 2 diabetes mellitus and metabolic syndrome: A systematic review and meta-analysis. Horm. Metab. Res. 52, 67-70 (2020).

287. Ulhaq, Z. S. \& Soraya, G. V. Anti-IL-6 receptor antibody treatment for severe COVID-19 and the potential implication of IL-6 gene polymorphisms in novel coronavirus pneumonia. Med. Clin. (Barc.). https://doi.org/10.1016/j.medcli.2020.07.002 (2020).

288. Wells, G.A., Shea, B., O’Connell, D., Peterson, J., Welch, V., Losos, M., et al. The Newcastle-Ottawa Scale (NOS) for assessing the quality of nonrandomized studies in meta-analysis. Ottawa Hospital Research Institute. https://www.ohri.ca/programs/clini cal_epidemiology/oxford.asp. (2011).

289. Luchini, C., Stubbs, B., Solmi, M. \& Veronese, N. Assessing the quality of studies in meta-analyses: Advantages and limitations of the Newcastle Ottawa Scale. World J. Meta-Anal. 5, 80-84 (2017).

290. Martorell-Marugan, J., Toro-Dominguez, D., Alarcon-Riquelme, M. E. \& Carmona-Saez, P. MetaGenyo: A web tool for metaanalysis of genetic association studies. BMC Bioinform. 18, 563 (2017).

291. Suurmond, R., van Rhee, H. \& Hak, T. Introduction, comparison, and validation of meta-essentials: A free and simple tool for meta-analysis. Res. Synth. Methods 8, 537-553 (2017).

292. Wallace, B. C., Schmid, C. H., Lau, J. \& Trikalinos, T. A. Meta-Analyst: Software for meta-analysis of binary, continuous and diagnostic data. BMC Med. Res. Methodol. 9, 80 (2009).

\section{Author contributions}

Z.U. conceived and designed the study. Z.U. and G.S. performed the study. Z.U., G.S., B., L.W. analyzed the data. Z.U. and G.S. wrote the main draft of the manuscript. B. and L.W. critically reviewed and give a suggestion to the manuscript. All authors reviewed and finally approved the manuscript.

\section{Competing interests}

The authors declare no competing interests.

\section{Additional information}

Supplementary information is available for this paper at https://doi.org/10.1038/s41598-020-74203-9.

Correspondence and requests for materials should be addressed to Z.S.U.

Reprints and permissions information is available at www.nature.com/reprints.

Publisher's note Springer Nature remains neutral with regard to jurisdictional claims in published maps and institutional affiliations.

(c) (i) Open Access This article is licensed under a Creative Commons Attribution 4.0 International License, which permits use, sharing, adaptation, distribution and reproduction in any medium or format, as long as you give appropriate credit to the original author(s) and the source, provide a link to the Creative Commons licence, and indicate if changes were made. The images or other third party material in this article are included in the article's Creative Commons licence, unless indicated otherwise in a credit line to the material. If material is not included in the article's Creative Commons licence and your intended use is not permitted by statutory regulation or exceeds the permitted use, you will need to obtain permission directly from the copyright holder. To view a copy of this licence, visit http://creativecommons.org/licenses/by/4.0/.

(C) The Author(s) 2020 